\section{Sobre límites y posibilidades de la investigación arqueológica de la arquitectura. De la estratigrafía a un modelo histórico}

\author{
LUIS CABALlero Zoreda
}

Consejo Superior de Investigaciones Científicas. Madrid

\begin{abstract}
Resumen
A comienzos de los años -90, diversas lecturas críticas sobre la arquitectura tardoantigua y altomedieval hispánica evidenciaron supuestas contradicciones en la teoría consensuada sobre su génesis y evolución. Personalmente, esta crisis de comprensión me obligó a un esfuerzo para resolverla, lo que dio lugar a que planteara un modelo explicativo nuevo, según el cual la revolución arquitectónica provocada por la nueva arquitectura visigoda se habría dado, en realidad, gracias a la aportación de la nueva cultura islámica, traspasada la Antigüedad tardía y ya en plena Edad Media. Al margen de otras connotaciones, en las que aquí no voy a entrar, esta postura me obligaba al desarrollo de una metodología específica para el estudio de esta arquitectura, de modo que, aplicándola a la resolución del problema planteado (del tipo falsación), se pudiera hablar con propiedad de un paradigma. Por ello profundicé en el conocimiento de la llamada arqueología de la arquitectura y la apliqué pretendiendo la resolución del problema.

Pasada una década desde aquel planteamiento, pretendo presentar mi experiencia sobre la utilidad y los límites de la arqueología de la arquitectura. Evidentemente, ha servido para la renovación del interés investigador sobre esta arquitectura y para la obtención de un nuevo corpus de datos novedosos, con un nivel de mayor rigor, pero no para resolver definitivamente el problema planteado que, como todo problema de carácter histórico, sigue en parte abierto y en continua renovación.

Usando diversos ejemplos, trataré de la relación yacimiento/edificio, estratigrafía muraria (secuencia constructiva, estratigrafía y estilo, estratigrafía e intervención, estratigrafía y diagnóstico), tipología y decoración, arqueometría, documentación y cronología absoluta.
\end{abstract}

Palabras claves: Arquitectura histórica, Arquitectura visigoda, Cultura Islámica.

\begin{abstract}
By the beginning of the 1990s, critical readings on late antiquity and early medieval Spanish architecture put into relief avowed contradictions in the generally accepted theories about its genesis and evolution. This crisis suggested me the need to propose a new explanatory model, according to which the architectural revolution brought about by Visigoth architecture would have taken place through the contribution of the new Islamic culture, way into the Middle Ages.

This approach prompted me to apply myself to Building Archaeology in order to turn it to the resolution of the problem.

A decade after that proposal I intend to present my experience on the usefulness and limitations of Building Archaeology. It has in fact proved useful in order to ensure a renewal of the research interest on this architecture and to obtain a new corpus of data on a more rigorous basis, but it has not been enough to solve the problem in a definite way since, as each and every historical problem, it remains partly open and subject to continued renewal.

Using different examples, I will delve on the site/building relationship, wall stratigraphy (building sequence, stratigraphy and style, stratigraphy and intervention, stratigraphy and diagnose), typology and decoration, archaeometry, documentation and absolute chronology.
\end{abstract}

Key words: Historical buildings, Visigoth architecture, Islamic culture.

\section{CONDICIONANTES DE UNA POLÉMICA}

\section{Objetivo}

Con este texto solo pretendo hacer una reflexión personal sobre mi experiencia con la llamada Arqueología de la A rquitectura. Responder a la pregunta ¿qué me ha enseñado 0 , mejor, qué he aprendido de la arqueología de la arquitectura?, real mente ¿para qué me ha servido?

He utilizado y desarrollado la arqueología de la arquitectura por necesitarla para resolver un problema histórico, concreto, planteado previamente (CABALlero, 1994-95). Ello hace que aparentemente pueda contrastar la investigación planteada, o sea el análisis y la interpretación, con los resultados obtenidos.

En este sentido me centro en analizar cuál es la principal ventaja o posibilidad que me ha facilitado la arqueología de la arquitectura, y cuál el límite con el que me he encontrado en su uso. Entre sus ventajas defiendo la utilidad de la estratigrafía, tanto para el análisis en sí mismo (en la toma de datos) como en la interpretación (o en la argumentación). Entre sus límites señal o especial mente la dificultad para asegurar un modelo explicativo, dificultad que creo se concreta especialmente en conseguir cronologías seguras.

Me refiero concretamente a mi caso, por lo que puede que condiciones subjetivas de la investigación (entre otras, mi propia comprensi ón de qué es arqueol ogía de la arquitectura) u objetivas del campo de estudio 0 , simplemente, la falta de perspectiva me impidan observar con claridad los verdaderos problemas con que me he cruzado o los verdaderos resul tados a que he podido llegar.

Los ejemplos en que me centro son conocidos y parecerán reiterativos, pero, escogido el tema como una reflexión de mi investigación con la arqueología de la arquitectura, es inevitable que esto ocurra.

\section{El modelo explicativo de partida}

El campo de estudio son dos posturas contrapuestas sobre el paso entre la tardía A ntigüedad y la al ta Edad M edia en la arquitectura hispánica.

La arquitectura altomedieval hispánica ofrece buen número de edificios de importancia, esencialmente religiosos, que han centrado líneas de investigación efectuadas durante más de un siglo procurando fecharlos y comprender la secuencia de su desarrollo histórico‥ Para ello se han utilizado modelos de análisis procedentes de la $\mathrm{H}$ istoria del Arte y de la Arquitectura, básicamente influidos por modelos previos historiográficos y por métodos filológicos (fuentes escritas) y estilísticos. Ello dió lugar a una expli- 
cación de esta arquitectura que, después de las primeras indecisiones, se acepta hoy como definitiva. La arquitectura paleocristiana, caracterizada por plantas basilicales con armaduras, a través de model os de transición, daría lugar a la visigoda o de época visigoda, del siglo VII, tendente a la planta centrada u organizada con espacios diferenciados e independientes, con aparejo de sillería, abovedada y decorada con escultura; y ésta, a su vez (a pesar del cambio socio-político que supuso la implantación del estado islámico), daría lugar, en el siglo IX, a la asturiana de aparejo de mampostería, bóvedas de ladrillo y decorada con escultura y pintura. La ruptura de esta secuencia, de raiz visigotista, continuista, vendría con la llamada arquitectura mozárabe, que introduciría el influjo islámico aportado por grupos de mozárabes huidos de al Andal us y asentados en la frontera cristiana del Duero a partir del siglo $X$, con tipologías variadas, abovedadas o con armadura, con el fósil director de sus capiteles y, en ocasiones, con escultura decorativa.

\section{Una propuesta alternativa}

A pesar de su aceptación general izada, este model o continuista presenta suficientes contradicciones como para que se haya planteado recientemente su revisión (R EAL, 1995, 2000; CA Ballero, 2000). Dos puntos son los más difíciles de explicar en el model o tradicional: uno, que las diferencias formales y estructural es entre los sistemas constructivos tardorromanos, de formas basilicales preparadas para cubiertas de armadura, y los visigodos y asturianos, de formas centradas preparadas para abovedarse; y otro, que la crisis del siglo VIII, con la llegada de un nuevo sistema político y social islámico, no sólo no influyera en las soluciones arquitectónicas y no interfiriera en la continuidad de esta evolución, sino que, de por sí, sirva para explicar la similitud existente entre la arquitectura visigoda y la asturiana.

A mi manera de ver, la relación entre lo visigodo y lo asturiano se entendería mejor si invirtiéramos el sentido de la evolución hoy considerada canónica, esto es, si los precedentes fueran las manifestaciones asturianas y los conse-

\footnotetext{
${ }^{1} \mathrm{~N}$ o podemos hacer aquí una síntesis de esta larga labor investigadora que, simplificando podemos sintetizar en las figuras de Lampérez, 1908; Gómez Moreno, 1906, 1919, 1966; Camps, 1940; Camón, 1950; Puig, 1961; SChlunk, Hauschild, 1978 y SChlunk, 1980; Palol, 1991; Bango, 1974 y ARBeiter, 2000. Sin embargo, debemos tener muy presente que las posturas de estos autores no son homólogas, existiendo diferencias entre ellas, que pueden considerarse incluso opuestas, como entre Gómez Moreno y Bango, por una parte, o entre Bango y Puig frente a los demás, en otro sentido. En la última década se han potenciado los estudios de carácter monográfico, especial mente de edificios urbanos considerados tardo antiguos.
}

cuentes, de repoblación, las hoy denominadas visigodas. De este modo se rellenaría con la arquitectura que hoy se considera visigoda el vacío de la activa producción arquitectónica que citan los documentos de la reorganización territorial de los reinos cristianos de la alta Edad M edia y que no puede explicar sól o la tardía edi licia llamada mozárabe. Además, a lo mozárabe se le achaca una relación directa con lo andalusí difícil de explicar y, al contrario, una compleja red de relaciones indirectas con lo llamado visigodo y asturiano, de modo que esta arquitectura no la considero una ruptura con los grupos anteriores, sino en reali idad el final de su evolución. Pero para aceptar la inversión de estos modelos (visigodo vs. repoblación) hay que demostrar que la tipología hoy en uso está mal fechada y que es posible cambiar el sentido de su cronología.

La toma de conciencia de estas contradicciones, especialmente la ordenación alternativa de paralelos formales y estilísticos y el análisis de su relación con las fórmul as constructivas y escul tóricas omeyas me ha permitido plantear un modelo explicativo distinto, 'catastrofista', que intenta resolverlas. Éste supone que el sistema conocido como arquitectura visigoda es en realidad una consecuencia de la implantación del estado andalusí en nuestro suel o, que aportaría con sus fórmul as arquitectónicas procedentes del arte omeya sirio una mezcla de influjos romanos orientales, bizantinos y sasánidas princi pal mente.

Frente a la teoría tradicional continuista, este modeIo propone una ruptura entre nuestro arte tardorromano y el alto medieval o prerrománico. En época visigoda, la arquitectura dependería de fórmulas evolucionadas tardorromanas sobre las que incidirían, sin duda, influjos mediterráneos que aún darían lugar a magníficas basílicas como la de Sta. Eulalia de M érida (M ATEOS, 1999) o la de la ciudad de Recópolis (Guadalajara). Pero las nuevas fórmulas, hasta ahora consideradas "visigodas", derivan de la aportación de la cultura omeya, especial mente el abovedamiento, la talla de los sillares, el uso del ladrillo o la recuperación de la escultura decorativa. $\mathrm{H}$ abría que redistribuir los edificios Ilamados "visigodos" entre los siglos VIII y X: unos como específicamente andalusíes o muladíes, de carácter civil, fechados circa 800, como las residencias de M orería en M érida (M ATEOS, AlBA, 2000: 156-164) y Pla de N adal en Valencia (JuAN, LeRMA, 2000); otros como mozárabes antiguos o dimmíes, iglesias de comunidades cristianas bajo dominio islámico, de la misma fecha que los anteriores, como El Trampal en Cáceres (CAballero, Sáez, 1999) y Melque en Toledo (Caballero, Fernández Mier, 1999); y finalmente el más numeroso como "de repoblación", iglesias bajo dominio cristiano, pertenecientes a 
comunidades cristianas que reorganizan políticamente la meseta superior, fechadas circa 900 y relacionadas con el arte asturiano, como Bande en Orense (CABALlero, 2001), la $\mathrm{N}$ ave en Zamora (CABAllero, ARCE, 1997), Baños en Palencia (CABAllero, Felj00, 1998) o el grupo riojanoburgalés, presidido por Quintanilla de las Viñas en Burgos (CABAllero, 1999). Parecidas técnicas y fórmulas fueron asumidas por grupos sociales muy diferentes, la sociedad fiscal islámica andalusí; la sometida sociedad cristiana dimmí; o las clases aristocrática y ecl esiástica de la naciente sociedad feudal cristiana.

El nuevo modelo explicativo no soluciona todas las contradicciones del hoy consensuado; al contrario, su evidencia de problemas irresolutos suponen para él, a la vez, caer en nuevas contradicciones. Unas, por ejemplo, las plantean los resultados de ciertos análisis arqueométricos a los que nos referimos al final de este texto. Otras, las fechas de ciertos edificios como los de la llamada cárcel de S. Vicente de Valencia (Ribera, Roselló, 2000; Sorian o, 2000) y del conjunto episcopal de Barcelona, con su iglesia cruciforme y su palacio (Bon net, Beltrán, 2001), o la iglesia de Val decebadar en Badajoz (U LBERT, 1973). Éste no es el lugar para discutir si es suficiente la coherencia de sus propuestas funcional es y estructurales o la fiabilidad de las dataciones arqueológicas de estos edificios, pero también es posible que estos 0 al gunos otros edificios considerados visigodos, incluso perteneciendo formalmente al grupo 'prerrománico', se adelantaran cronológicamente a su momento histórico, antes de la crisis del 700 que supuso la implantación islámica con sus nuevas condiciones sociales y la consecuente oportunidad para un nuevo y revolucionario sistema constructivo.

\section{Condicionantes}

La postura que ll amo tradicional o consensuada tiene unos condicionantes. La responsabilidad de estos condicionantes se debe en su mayoría al estado de la investigación en el momento en que se desarrolló ese modelo explicativo y a la técnica de anál isis el egi da para defenderla. Otra cuota de responsabilidad corresponde al propio model o y objeto de estudio y al modo de argumentar utilizado por sus defensores.

- Salvo excepciones, un método fundamentalmente de carácter estilístico, que considero pretipológico.

- Ausencia de estudios estratigráficos. En gran parte no es si quiera un anál isis pre-estratigráfico, sino a-estratigráfico. - Los dos puntos anteriores la hacen deudora en gran parte de los estilos decorativos, dado que para esta postura, la decoración se convierte obligadamente en fósil director. La ausencia/presencia de unos u otros el ementos decorativos determina la ubicación como objeto histórico/cultural de cada producto arquitectónico.

- Ello da lugar a un exceso de paral elismos. Los paralelos son definitivos para datar o para encuadrar o para comprender el resto que se analiza, arrastrando los errores de los model os paral elizados.

- Finalmente y de nuevo a causa de los mismos hechos, depende estrechamente de los datos documentales, tanto de los externos, los documentos que hablan sobre el edificio (como Bande), como de los internos, presentes en el mismo edificio (la inscripción de Baños).

Téricamente la propuesta al ternativa que defiendo pretende fal sar o contrastar el modelo tradicional presentando un modelo al ternativo dispuesto a sustituirle. Cada nueva propuesta o proyecto de investigación, ya sea de falsación o de demostración de una hipótesis, necesita plantear una metodología apropiada a su análisis. Veámos qué conlleva esta posición.

- La búsqueda y utilización, a propósito para defender esta postura, de la Arqueología de la Arquitectura, como método y como ciencia.

- La colocación de su punto de partida en un problema histórico. Interesado por la arquitectura y haciendo arqueología de la arquitectura, el interés final es un problema histórico, no arquitectónico. No interesa como objetivo conocer el objeto arqueológico, ni el producto arquitectónico, ni exactamente su proceso de producción, sino conocer mejor el proceso de cambio entre la tardía antigüedad y la al ta Edad M edia a través de la arquitectura.

- El problema cronológico. Sin embargo se necesita un cedazo cronológico donde col ocar los datos para hacer esta interpretación histórica. Esta consecución cronológica es la que más esfuerzo cuesta y la que más interfiere en la interpretación histórica, pues se sitúa en la base de la contrastación del modelo tradicional al sintetizarse en la pregunta por la fecha, "¿es del siglo VII o del siglo VIII o del siglo IX ?"2.

- A unque prima el interés científico por poner en duda un modelo explicativo, y esto es así; también ocurre que es la

\footnotetext{
2 Quizás podría haber elegido otro método, como el de la Arqueología de la Producción. Es posible que el empeño en resolver ante todo el problema cronológico, que parece el prioritario para seguir avanzando con otros planteamientos, impida aprovechar otras posibilidades. Debemos preguntarnos si es posible, por ejemplo, una arqueología de la producción sin un esquema cronológico contrastado previamente 0 , al contrario, si es posible que la aplicación de otra metodología, como la dicha, esté mejor preparada para resolver las cuestiones cronológicas sin tener que acudir, al menos exhaustivamente, a los métodos clásicos de datación.
} 
propia ausencia de una metodología "moderna" en el model o a falsar, la que pone en duda todo el modelo por sí misma. Digamos que de nada vale el modelo consensuado si es imposible hacer compatible su metodología con la metodol ogía usada ahora. 0 sea, aunque no hubiera rechazado de entrada el modelo consensuado, habría que rechazarlo o darlo de lado una vez que se decide utilizar un nuevo método de estudio como la arqueol ogía de la arquitectura, puesto que no es parangonable el método de estudio del paradigma tradicional, preestratigráfico, con el nuevo método de estudio que impone de por sí un nuevo paradigma. Esta es para mí una de las conclusiones más interesantes de mi experiencia: resulta curioso comprobar que no puedo utilizar mis propios estudios anteriores al no alcanzar el rigor estratigráfico que ahora requiero (por ejemplo Bande y M el que, Caballero, LatorRe, 1980). Es en un doble sentido, técnico y científico, una vuelta a empezar ${ }^{3}$.

- T écnica y ciencia a la vez. M i experiencia se coloca dentro de la vieja polémica entre técnica y ciencia, pues las necesito conjuntamente, entre "arqueografía" o arqueología e historia; entre los datos y las hipótesis, entre la construcción de unos nuevos objetos arqueológicos y la comprensión o interpretación de esos objetos (GUTIÉRREZ LLORET, 1997: especial mente 28-39). ¿Por qué? Porque al partir de cero, por un lado se necesita, antes de intentar otra interpretación, revisar o redescribir de nuevo los objetos, al invalidarse las antiguas lecturas; y porque, por otro lado, se necesitan nuevos datos sobre los que apoyar las nuevas argumentaciones.

De hecho doy los dos pasos a la vez. En mi experiencia me es imposible separar estas experiencias, técnica y científica, arqueológico e histórica, sino que van íntimamente unidas. Aunque me parezca que lo primero que se me planteó fue la duda científica o histórica, esto es, la duda sobre el model o explicativo, sin embargo es posible que primero se me planteara el nuevo método (CABALLERO, 1987/1992), la arqueología de la arquitectura, y que fuera ésto lo que me facilitara afrontar con cierta posibilidad de éxito el nuevo análisis.

Sin el nuevo método no podría falsar el modelo antiguo pues tendría que haberlo intentado con su mismo método. Esto es evidente, se trata de un paradigma nuevo no sólo por tratarse de un modelo alternativo, sino también por la utilización de un nuevo método, la arqueología

\footnotetext{
${ }^{3}$ U na vuelta a empezar dicho con sentido retórico. Soy consciente de que la labor de investigación previa es base de la futura; pero también es evidente que, sobre el revulsivo de lo ya efectuado, la nueva labor supone un replanteo.
}

de la arquitectura, en el que se coloca a la cabeza el instrumento estratigráfico.

A hora bien. I gual que en el modelo consensuado hay unos condicionantes que constriñen sus resultados, en mi modelo tiene que haber otros condicionantes limitadores que se deriven, justamente, del nuevo método planteado para resolver los condicionantes del antiguo.

\section{La cuestión de partida y el punto de llegada}

$\mathrm{N}$ o se pretende simplemente cambiar la fecha de unos productos arquitectónicos, de antes del año 711 a después del 711 , sino explicar la desaparición de un tipo y su sustitución por otro tipo distinto y, desde luego, cuándo se produjo, cómo se produjo y por qué se produjo este cambio. $\mathrm{N}$ o se trata de un problema cronológico aunque éste se empeñe en colocarse en primer término.

En este sentido, adelanto que no he conseguido una solución definitiva y categórica, tanto se entienda por ello una conclusión de carácter cronológico, como de carácter histórico socio/cultural. Aunque se debe diferenciar por un lado mi propia opinión, lo que yo piense y defienda, y por otra, muy diferente, lo que halla conseguido demostrar y lo que se acepte corporativamente como tal.

\section{LA ESTRATIGRAFÍA}

\section{La revolución estratigráfica}

El uso de la estratigrafía en la resolución de este problema provoca una reacción tan fuerte que impide la consecución directa de soluciones definitivas, al colocar el problema en un punto de partida cero.

La estratigrafía desmonta la argumentación preestratigráfica 0 , lo que a efectos prácticos es 10 mismo, coloca esa argumentación en una vía divergente sin posibilidad de relacionarlas entre sí. Las conclusiones de uno y otro paradigma, en cada caso concreto, difícilmente son parangonables y las posturas quedan como irreconciliables. A hora bien, en este punto no val e nada más que una solución absoluta al problema, no se permite que queden cabos sueltos. A partir de este punto cero, la solución tiene que venir para todo el sistema, no basta con conseguir soluciones para aspectos parciales de él. Por ello advierto que, aunque estoy plausiblemente seguro del modelo explicativo que defiendo, no he conseguido una solución definitiva. Sólo la acumulación de nuevas y rigurosas lecturas estratigráficas podrán decantar la solución a favor de uno u otro modelo.

De lo que acabo de decir podría deducirse que el instrumento estratigráfico no sirve para resolver la 
cuestión histórica y que se debería sustituir por otras al ternativas arqueológicas. A mi parecer esto no es así. La estratigrafía supone la imposición de un rigor descriptivo y analítico imprescindible y previo a cualquier otro tipo de anál isis y previo también a la argumentación propiamente histórica. La estratigrafía es la columna vertebral de nuestros estudios y solo en tanto que esto se acepte y se aplique así por el cuerpo de profesional es, se dará un avance significativo de la arqueología de la arquitectura (A RCE, 2001: 263 y 270 ).

\section{Estratigrafía frente a decoración y documento escrito}

El análisis estratigráfico desmonta el análisis preestratigráfico de estas iglesias, el val or como fósil director de su decoración y el valor cronológico otorgado por el documento escrito fechado:

- El análisis pre-estratigráfico se demuestra poco riguroso y queda como una especie de borrador abocetado y borroso por más que, en sí, pueda ser genial.

- La tipología de la escul tura decorativa se demuestra que, por lo menos en este momento de puesta a cero de la investigación, no existe si no es dentro de una lectura estratigráfica. Cada edificio, cada estrato del edificio tiene su propio fósil director (huellas de trabajo, aparejo, decoración, estructura) que sól o la lectura estratigráfica define. - El documento escrito, como todos sabemos, no puede utilizarse sin una previa contextualización objetual y lectura crítica documental.

\section{Santa Comba de Bande (Orense)}

Bande es un ejemplo de lo que llamo "edificio/modelo" de la arquitectura visigoda, convertido en tal por su referencia documental. Según un documento del siglo XIII, la iglesia había sido restaurada en el año 872 por aristócratas asturianos, tras un abandono de doscientos años (Fray Benito de la Cueva en 1638, recogido por Gonzáles BALASCH, 1991: 61-63 y 76).

- Este dato sirvió para que desde Lampérez (1908: 153156) y la intervención restauradora en el edificio (GómEZ MOREN 0, 1943-44) se datara como visigoda del siglo VII (872, menos doscientos años, luego aproximadamente 672).

- Pero Bande ofrece contradicciones que, aunque no aceptadas como tales, sirvieron para afinar la argumentación "continuista" (CAMÓn, 1963: 214). El edificio ofrece variantes muy acusadas respecto a la ti pología clásica de los edificios visigodos, como tipos diferentes de aparejo (sillería reutilizada), estructuras (bóvedas de ladrillo) y decoración (capiteles y frisos). El modelo tradicional asume perfectamente estas variantes como precedentes de la producción arquitectónica asturiana dos siglos posterior, aunque es evidente que estas variantes se explican mejor como indicios de su cronol ogía tardía que como antecedentes de Io asturiano. Así que la presencia de capiteles de estilo asturiano, de bóvedas de ladrillo de tipo asturiano o mozárabe y de huellas en el edificio (hoy diríamos interfaces constructivas) hizo que se buscara una segunda interpretación más acorde con el propio documento: considerar una parte del edificio visigodo y otra reconstrucción de Reconquista. Para N uñez (1978: 86-94) los capiteles eran asturianos; para Palol (1968: 148-150) es de Reconquista toda la cubierta, diferenciada por la imposta asturiana, y para Kingsley y para mí lo era, al menos, el ábside (KIn GSLEY, 1980: 183 SS.; Caballero, 1991: 92-110).

- Sin embargo, la lectura estratigráfica ll eva la contraria a estas explicaciones (CABallero \& alii, 1999; Caballero, 2001). Demuestra que el edificio es uniforme incluyendo los cimientos, los muros desde el ábside al porche, la decoración y su abovedamiento. El edificio se conserva completo a excepción, resumiendo, de las restauraciones que necesitaron las hojas externas de los muros que, mal atadas para aguantar la presión de las bóvedas, terminaron pandeándose, lo que obligó a restaurarlas antes de que su ruina afectara la integridad del edificio. Por lo tanto las variantes con el tipo visigodo no deben considerarse ni precedentes ni indicios de reconstrucciones del edificio original, sino fósiles directores que datan el edificio en un momento posterior.

El resultado estratigráfico cuestiona las explicaciones precedentes:

- Mi análisis preestratigráfico del edificio (CABAllero, LATORRE, 1980), por poco riguroso y asistemático. Las huellas (interfaces) en el edificio se deben a otras causas, no a una restauración del siglo IX.

- La argumentación estilística y tipológica, pues de ella no se pueden deducir automáticamente ni dos momentos constructivos en el edificio, que no existen, ni su cronología.

- La argumentación documental que entra en contradicción con la lectura estratigráfica, pues no se descubre la etapa de reconstrucción que debería considerarse existentet. N o se consigue una explicación que relacione unívocamente los datos del documento con los del edificio. Pudo existir un edificio previo o no haberlo; y el documento

\footnotetext{
${ }^{4}$ La única obra efectuada en esta etapa al tomedieval fue la apertura de un altarnicho en el brazo derecho de su crucero, que no se puede considerar una reconstrucción.
} 
puede fal sear la real idad o puede que no entendamos exactamente a qué se refiere.

Y plantea automáticamente una propuesta al ternativa: - Las impostas no son visigodas, sino asturianas por sus paral el os estilísticos.

- Las bóvedas no son visigodas, sino asturianas o mejor mozárabes como en el cercano paralelo de Celanova del siglo X (Gómez Moren 0, 1919: 248).

- El documento no narra exactamente los hechos, sino que los manipula para defender los derechos de propiedad del monasterio de Celanova del que depende la igl esia. La referencia a "hace doscientos años" puede si gnificar un genérico como "desde tiempo inmemorial" que es lo que se pretende demostrar.

A hora bien, ¿el uso de la estratigrafía consigue un resultado definitivo? y ¿es correcto hacer uso, de nuevo, de paral elos estilísticos o tipológicos?

El resul tado de la estratigrafía sólo afirma que las lecturas del modelo visigodo no son válidas; pero la nueva argumentación no se deriva únicamente de la estratigrafía cuanto también del método tipológico usado como propio por el modelo primitivo. Dicho de otro modo, la estratigrafía no demuestra la argumentación, sól o la contextual iza y la obliga a un mayor rigor, pero ni la aprueba ni la demuestra. La explicación puede volver a ser alternativa desde otros planteamientos y con el uso de otros instrumentos, como el tipológico. Bande puede seguir siendo visigodo 0 de Reconquista siempre que la nueva explicación se mantenga dentro del nuevo marco estratigráfico mucho más riguroso y por ello más ajustado.

La verdadera conclusión es la propuesta de un nuevo proyecto de investigación:

- La interpretación de Bande debe hacerse a la luz de un estudio riguroso de la arquitectura asturiana y mozárabe, de sus estratigrafías, de sus bóvedas, de sus impostas y capiteles.

- Antes de utilizar el documento escrito, debe hacérsele una crítica textual rigurosa. La nueva interpretación del edificio obliga a pensar o que el texto o su información pueden estar manipulados o que la estratigrafía es incapaz de descubrir la restauración que cita; bien porque sea imperceptible 0 , al contrario, porque se trate de edificios distintos o porque sea una restauración total, una sustitución a fundamentis.

\section{San Juan Bautista de Baños (Palencia)}

Es otro "edificio/modelo" visigodo por poseer una inscripción que data su construcción por el rey Recesvinto en el año 661 (no sin problemas, GIL, 1978). Con ella se fecha además el fósil director de la escultura. La conclusión para el modelo visigotista ha sido inmediata, Baños es el fósil director de la escultura visigoda: toda la escultura similar a Baños y por ende todos los edificios que la tengan tienen que ser visigodos (SCHLUNK, 1945: 253-254; Gómez Moren 0, 1966: 123-124; JORGE, 1957; SCHLUNK, 1970: 175-186).

En un primer momento se considera el edificio y su inscripción unitario, sin plantear una posible yuxtaposición de elementos. Pero, en un proceso paralelo al de Bande, nuevos hallazgos obligan a complicar la reflexión. U na aparente distinción de dos grupos de escultura decorativa (por temas, los cuadrifolios del ábside central frente a las trenzas de los ábsides laterales) hace pensar en dos etapas constructivas, una visigoda formada por el aula y el ábside central y otra por la adición de los ábsides laterales (PALOL, 1988: 23 y 53).

Por otra parte, la endeblez del argumento "epigráfico" es tal que la consecución de nuevos datos provoca el planteamiento de una nueva hipótesis tardo medieval, gótica, basada en el dato contradictorio de que la inscripción se hallaba en el siglo XVI en San Román de Hornija (Zamora) y en el simbolismo godo buscado por los $M$ anrique, propietarios del edificio en esta época (Velázquez, Hern ando, 2000; Sán chez García, 2001). Sin embargo esta propuesta debe rechazarse pensando en una equivocación del informador renacentista. Es imposible pensar en la construcción de un edificio gótico (tardomedieval) con caracteres historicistas tardoantiguos 0 al tomedieval es. Lo que llama la atención de este caso es la fuerza del "argumento epigráfico" que tienta a su aceptación inmediata sin entrar en su crítica rigurosa. A demás, la lectura estratigráfica (CABAllero, Felj00, 1998) contradice en primera instancia su aceptación, pues distingue dos momentos perfectamente separados en su secuencia histórica: el original, manteniendo en él la colocación de la inscripción del 661 tal como está (sea de la cronología que sea esta etapa original), y el momento de restauración tardomedieval, que se puede acomodar al momento gótico, pero que nada tiene que ver con la colocación de la inscripción.

La lectura estratigráfica discrimina las abundantes restauraciones del edificio, entre ellas la principal gótica a que nos hemos referido y una anastilosis de mediados del siglo XIX (SÁnchez García, 2001: 24-26). La lectura, a su vez, permite reconstruir la forma perdida del edificio original.

Pero la lectura estratigráfica también describe con rigor la escultura decorativa, lo que permite ordenar tres 
grupos escultóricos en el edificio original (CABAlLero, FeIJ00, 1998: 223-229; ARCE, 2001: 266-270). Uno primero, escaso y reutilizado, en el que todos estamos de acuerdo que es de época visigoda; otro segundo (los cuadrifolios y trenzas de talla a bisel), reutilizado, incluido en el edificio, y estilísticamente de fecha discutida; y otro tercero que imita al segundo, retalla sus piezas y ofrece otros model os de un estilo distinto (tall la plana, temas inorgánicos, palmetas, alfices) para los que, a mi modo de ver, se pueden encontrar paralelos en la decoración asturiana del siglo IX y castellana del X. Este tercer grupo, y no la inscripción, es el fósil director de la etapa original, tallado para decorar el edificio y que, por tanto, debe fechar el edificio.

De esta manera, de nuevo, la estratigrafía cuestiona la argumentación preestratigráfica. Primero cuestiona la fal ta de rigor descriptivo. Su val or no se agota en una estratigrafía rigurosa, pues sin la descripción aneja hubiera sido imposible relativizar la escultura decorativa que ahora resulta que se distribuye en tres grupos productivos o culturales distintos. Por lo tanto, una parte del estudio productivo debe su planteamiento, en este caso, a la estratigrafía. Y, en tercer lugar, es capaz de rel ativizar el val or del documento inscrito que no sabemos a cuál de los tres grupos productivo/cultural es pertenece; esto es, dicho en términos estratigráficos, si es un "material incluido" procedente de otro edificio anterior o si es un "fósil director" coetáneo al edificio original.

La inscripción, a nuestro parecer, pierde su valor, regresa a un punto cero. Puede significar el poder de la monarquía visigoda para dotar esta fundación; o servir para demostrar la buscada relación de la aristrocracia de reconquista (asturiana o leonesa) con sus míticos antecesores visigodos, esto es el espíritu neovisigotista, según el modelo de la cultura principesca medieval enunciado por los Grabar (1965). ¿Qué significado tendría entonces?, ¿solo un significado simbólico, una especie de reliquia?, ¿o también se "imitaron" las formas constructivas, igual que se imitó la decoración?

Finalmente, se pone en cuestión la cronología de la escultura decorativa, por definirse varios grupos y dudarse de la relación de originalidad (en el sentido de perteneciente al origen) de la inscripción con el propio edificio. El segundo grupo decorativo puede ser tanto visigodo como post-visigodo. La relaciones tipológicas o estilísticas se ponen también en duda y podemos preguntarnos hasta qué punto son legítimas. Al menos teóricamente, este grupo puede tener una cronología relacionada con el grupo constructivo asturiano. D ebemos preguntarnos por la pro- cedencia de este segundo conjunto decorativo, de su material, de su edificio, de su lugar y cronología. Ofrecen interesantes cuestiones su proceso de sel ección, desmonte, si lo hubo, y traslado. Pero, sobre todo, ¿es legítimo seguir recurriendo a paralel os estilísticos asturianos pre-estratigráficos para datar el tercer grupo como del siglo IX?, ¿no es obligatorio pasar previamente por el tamiz estratigráfi$\mathrm{co}$ al grupo productivo asturiano donde se encuentran esos paral el os?

Todas estas preguntas proponen un "proyecto de investigación" que abarca desde el tipo de material empleado (la relación existente entre el de la inscripción y el de los distintos grupos decorativos), la tipología o el estilo decorativo (reordenado sobre la col umna vertebral de la estratigrafía) y el grupo productivo asturiano con su decoración y sus paral elos estilísticos.

\section{La arquitectura prerrománica abovedada}

Una de las posibilidades de la Arqueología de la A rquitectura es la de reconstruir las estructuras Ilegadas a nosotros incompletas. No sólo la de tratar los restos conservados a través de las secuencias constructiva y tipológica, si no la de imaginar con verosimilitud las estructuras originales y usar el resultado como otro dato más. Esto permite conseguir otra secuencia, la serie estructural, en un nuevo paso hacia el estudio de la producción arquitectónica. Propuesta la serie, se buscará una explicación para ella, superando la mera inclusión de tipologías en el modelo explicativo, con mayores posibilidades argumentales. A su vez, podremos acercarnos a una producción estructural, superando también el estudio aislado de productos de talla, producción de aparejos o de el ementos singulares.

El análisis estratigráfico supone una diagnosis meticulosa del edificio y por lo tanto permite imaginar el edificio perdido a partir de sus el ementos conservados y de las huellas dejadas en ellos por la pérdida de los elementos desaparecidos. En las iglesias de Arlanza (CABALlero et alii, 1991/92), S. Vicente del Valle, La N ave y Quintanilla (CAballero, ArCe, 1997: 260-267) y El Trampal (CAballero, Sáez, 1999) es el tipo de ruina (caída de bóvedas y muros, desplazamiento de sillares, inclinación de muros, rotura de testeros 0 de dinteles de las puertas, grietas) Io que ayuda a reconstruir el sistema constructivo; esto es, los arcos en las pilastras adosadas, las arcadas en las naves y sobre el las la cubierta abovedada.

La sistemática conservación de las bóvedas en los ábsides y, en ocasiones, en las cabeceras y la presencia de armaduras (de restauración) en el cuerpo de las iglesias 


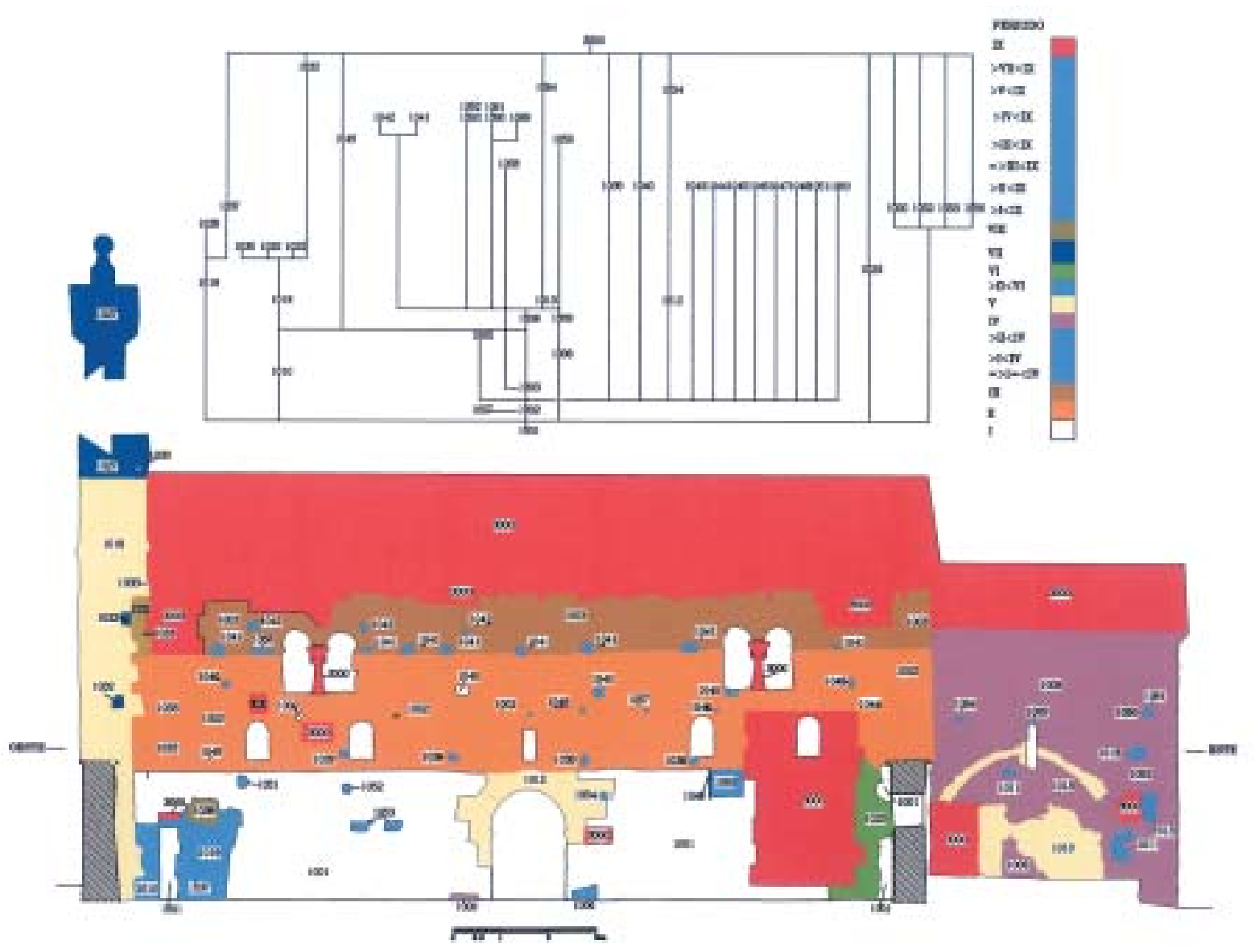

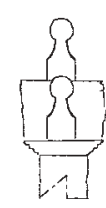

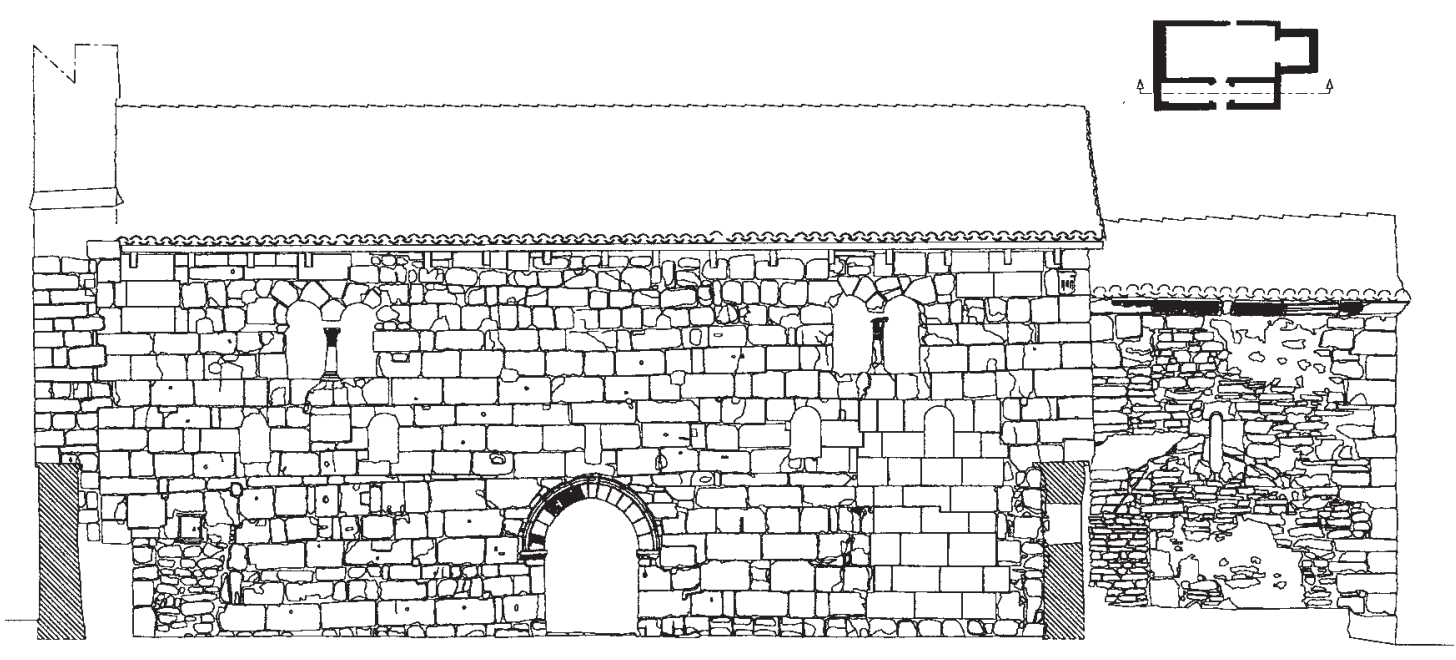


'visigodas' hizo imaginar a la explicación tradicional que al ternaban en ellas los dos sistemas constructivos, cabeceras abovedadas y naves con armaduras. Sin embargo, los nuevos datos inferidos permiten afirmar que, en la mayoría de los casos, estuvieron completamente abovedadas, apoyando la conclusión con la comparación y extrapolación al resto del grupo. Se puede proponer que fue el ensayo del novedoso sistema de abovedamiento lo que hizo que sus empujes mal equilibrados provocaran las ruinas en un proceso iniciado, en unos casos, a poco de construirse y prolongado, en otros, hasta nuestros días tras series de continuas ruinas y reconstrucciones. Algunas, como A rlanza, S. Vicente del Valle (fig. 1) y Tobillas, se restauraron de inmediato con sistemas prerrománicos, incluso en varias ocasi ones, mientras que las más se restauraron con sistemas que no tenían en cuenta e incluso variaban el sistema original, como ocurrió en La N ave y EI Trampal. Los resultados permiten la reconstrucción ideal de los edificios originales.

Ello permite proponer un nuevo grupo burgalés, riojano y vasco de iglesias altomedievales, caracterizadas por el ábside cubierto con bóveda sobre pechinas y el aula de tres naves abovedadas (CABALlero, 1999). H asta ahora este grupo estaba disperso, pues unas se daban como visigodas, otras como mozárabes y otras pasaban inadvertidas. Además, al grupo se añade Quintanilla de las Viñas, otro edificio/model o visigodo. También se recupera la ol vidada propuesta de Torres Bal bás (1933: 131-132) del abovedamiento de La $\mathrm{N}$ ave (fig. 2), cuyo hundimiento provocó tal descabalamiento del edificio que hizo equivocarse a Gómez M oreno (1906) cuando auguraba que sería imposible su restauración.

Finalmente, se puede proponer la reconstrucción de la del Trampal (fig. 3), como un sistema completamente abovedado, aunque debo advertir que no todas las opiniones están de acuerdo con esta propuesta (CABA LleRo, SáEZ, 1999: 100-106). Personal mente creo que sus soportes constituyen un sistema preparado para abovedar, y que es incoherente colocar vigas sobre los arcos adosados, sus minúscul os espacios intermedios y las estrechísimas naves laterales.

Esta característica, abovedada, es una de las que, para mí, impide la consideración de esta arquitectura como tardoantigua, definiéndola como prerrománica. Además creo

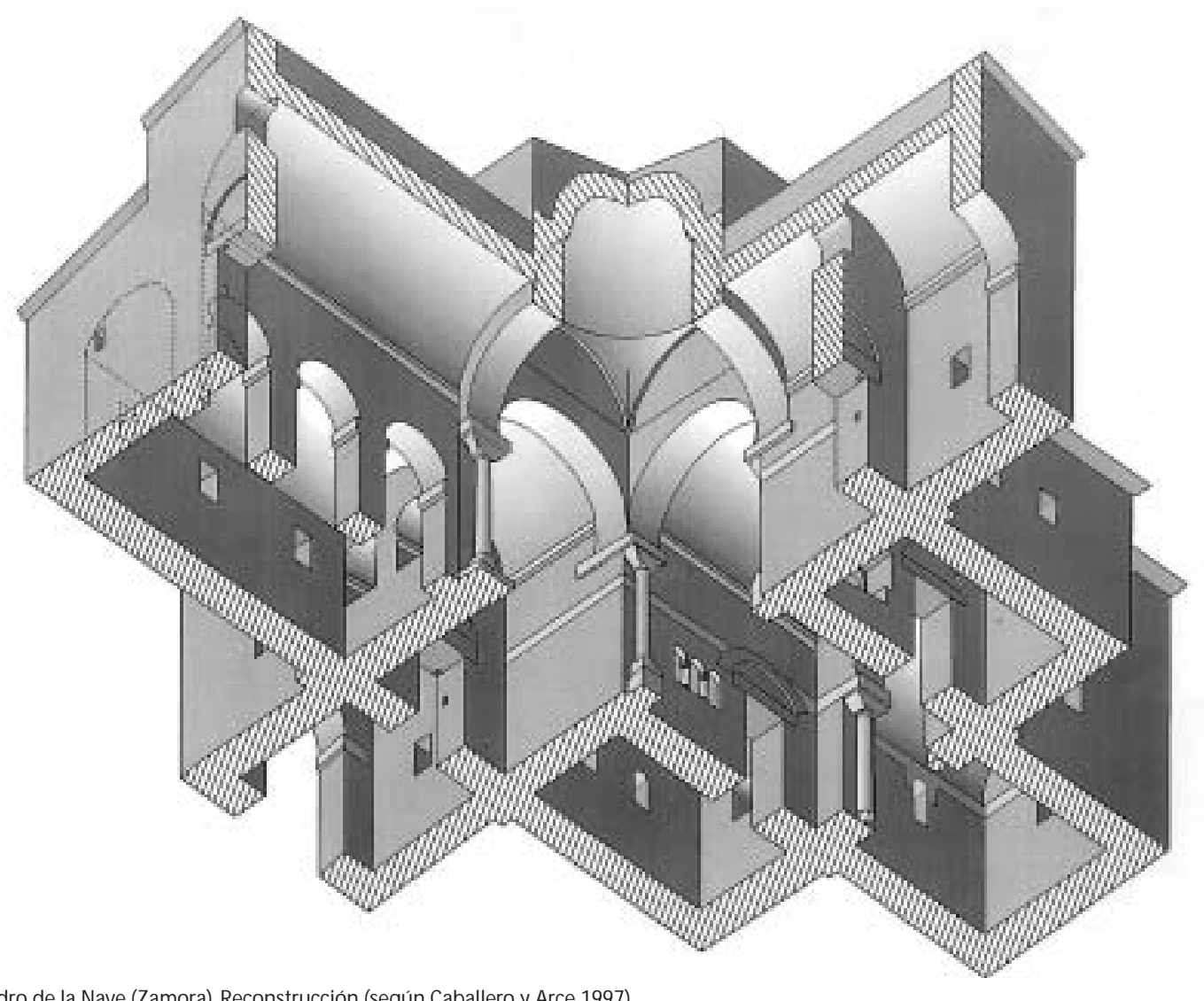

Fig.2. Iglesia de S. Pedro de la Nave (Zamora). Reconstrucción (según Caballero y Arce 1997) 


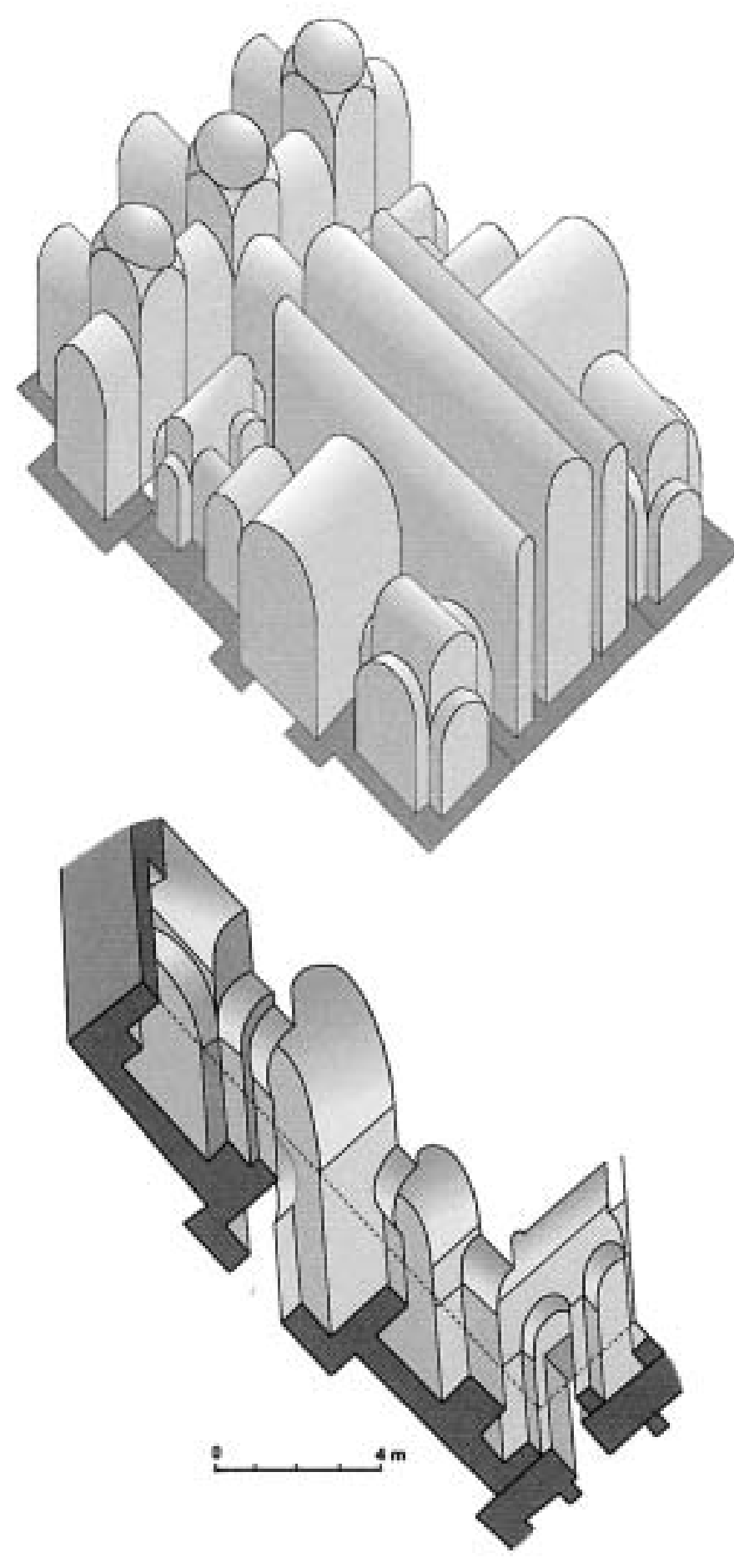

Fig.3. Iglesia de Sta. Lucía del Trampal (Cáceres). Reconstrucción (según Caballero y Sáez 1999) que impide pensar la evolución desde la arquitectura basilical tardoantigua y obliga a aceptar una revolución provocada por un sistema productivo distinto. El subgrupo burgalés/riojano es uno más en el amplio grupo prerrománico conformado por subgrupos de distintas fechas y adscripciones, como el asturiano del siglo IX y el llamado mozárabe del Duero, de los siglos X y XI, distinguidos de antiguo; el posible extremeño, señalado ahora sólo por EI Trampal, y otros a los que deben pertenecer edificios sueltos como La N ave o Baños en la Meseta, Melque en La $M$ ancha y otros portugueses, como S. Giâo de $N$ azaré.

\section{LA LIMITACIÓN CRONOLÓGICA}

H emos visto hasta aquí al gunas posi bilidades que tiene la arqueología de la arquitectura basada fundamental mente en la estratigrafía como riguroso elemento anal ítico estrechamente unido e indisoluble a la interpretación. A hora quiero entrar en los límites que presenta.

\section{La cronología}

Aunque la cronología no es el objetivo, es innegable su importancia en este debate científico. Se necesita un marco o una urdimbre en la que tejer el nuevo model o explicativo. $Y$ este marco debe ajustarse a una cronol ogía rigurosa. ¿0 realmente no es necesaria?, ¿puede ser aparente esta necesidad de un marco cronológico?, ¿puede ser un falso reflejo del paradigma antiguo?, ¿se puede actuar desde la arqueología de la arquitectura sin asegurar primero la cronología real de los edificios? Creo que no, que es imposible. No se busca la cronología, pero sin ella no se puede avanzar ningún paso.

No se puede olvidar la "imperiosa necesidad" de cronología (como la denomina Gar Cía De CORTAZAR, 1988: 236), más para un caso de contraste o fal sación como éste. Recuerdo el asombro de un colega romano que, ante mi duda cronológica, se vió obligado a afirmar la fal ta de cal idad de nuestra arqueol ogía, tan retrasada que, a estas al turas, es incapaz de datar estos edificios. La falta de cronología en su marco de referencia es al go no permitido a un historiador.

La estratigrafía, junto a sus posibilidades, posee una limitación fundamental, la de sol o ofrecer cronología relativa y por lo tanto la de depender de otros instrumentos para conseguir una cronología absoluta. Existe una mutua dependencia entre la estratigrafía y los instrumentos de cronología absoluta. A mi modo de ver, los segundos dependen necesaria y previamente, en cualquier caso, de la estratigrafía, necesitan una "contextualización" previa. 
Pero también la estratigrafía necesita de estos instrumentos para engarzarse en una malla cronológica. La estratigrafía es una columna donde se apoyan los demás datos, un marco previo que aporta una "puesta a cero" de los problemas y rigor en su planteamiento, con la severa limitación de su ausencia de cronol ogía absoluta. Las fuentes escritas, la ti pología y los análi isis arqueométricos aportan esta cronología absoluta aunque ésta viene limitada por necesitar una rigurosa contextualización estratigráfica, además de por las propias limitaciones de sus sistemas de análisis y calibración. La tipología, en concreto, depende estrechamente de la estratigrafía que es quien en primera instancia ordena sus secuencias. Las contradicciones existentes entre los grupos de conclusiones de cada uno de estos instrumentos plantean nuevos proyectos de investigación, cada uno con su personalidad derivada de la circunstancia que provocó su planteamiento, o, incluso, el replanteamiento del model o y el paradigma (fig. 4).

\section{El caso de las iglesias de Tobillas (Álava) y Quintanilla (Burgos)}

En relación con el problema de las cronologías debo referirme al pionero estudio de la iglesia al avesa de Tobillas efectuado por A gustín Azkarate (1995). Es una iglesia del grupo de las burgalesas y riojanas, con ábside con bóveda sobre pechinas, cuyas dos primeras etapas data Azkarate,

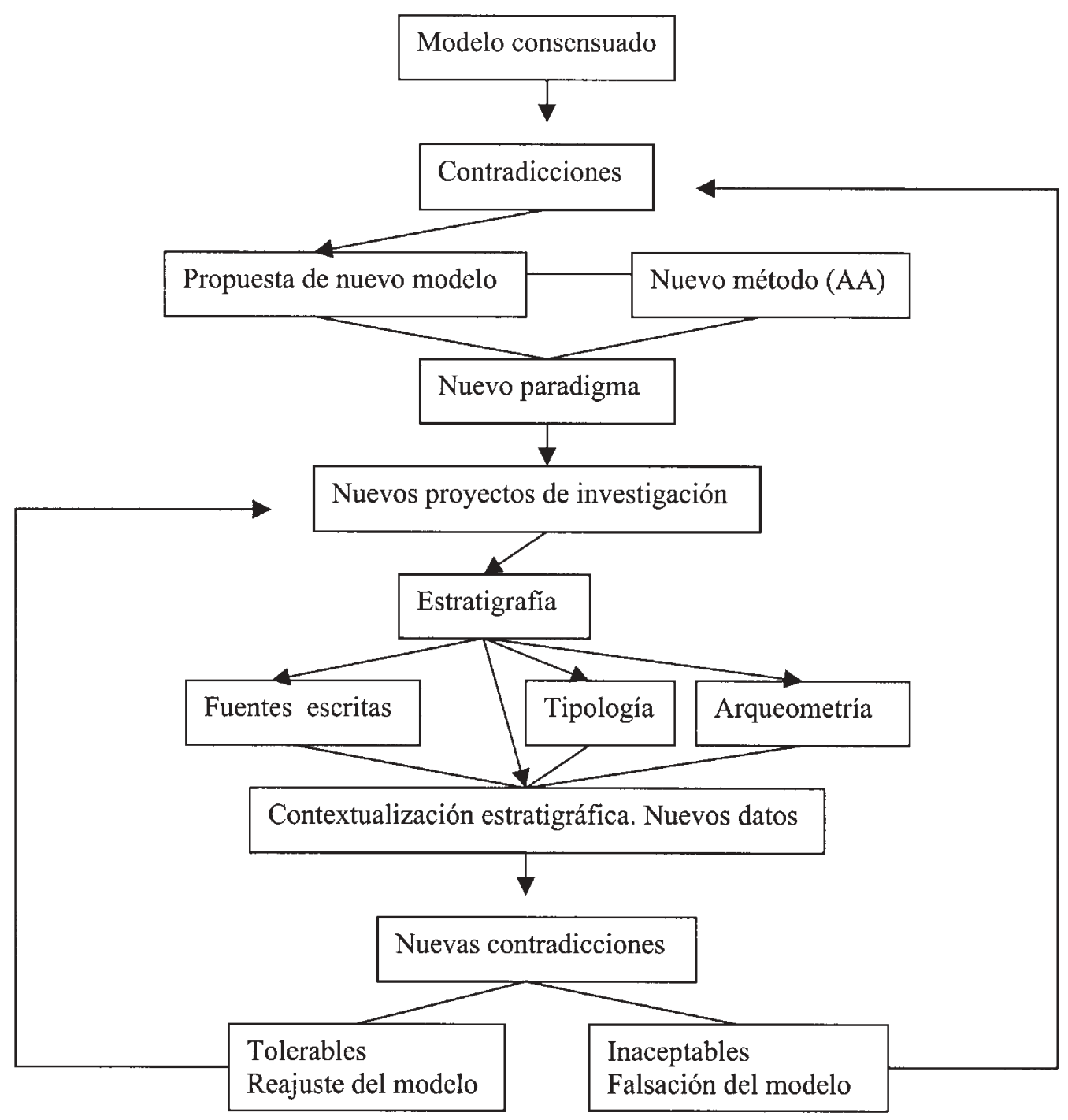



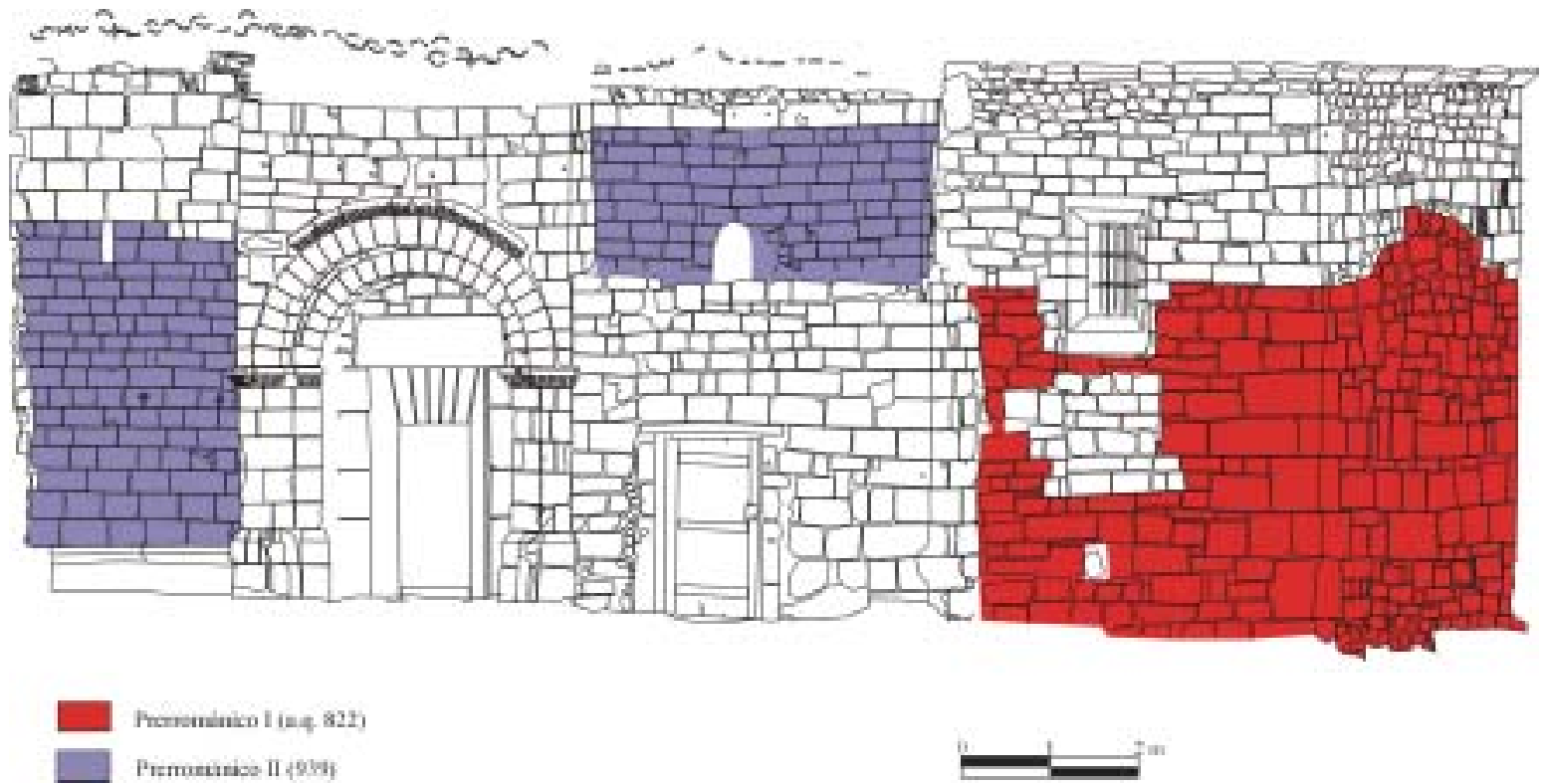

Fig.5. Iglesia de San Román de Tobillas (Álava). Lectura de la sección hacia Sur (según Azkarate 1995)

en una interpretación concorde con nuestro modelo y con los datos documentales, en a.q. 822 y 939 (fig. 5). La primera fecha es la del testamento del abad Avito quien tras construir la iglesia, la dota magníficamente. Lo curioso es que entre esas dotaciones se sitúa Santa M aría de Lara, considerada Quintanilla de las Viñas (PEÑA, 1995: 109110). Quintanilla es una iglesia burgal esa del mismo tipo constructivo, con bóvedas sobre pechinas, aunque su aparejo es distinto, de sillería reutilizada y recortada, que en ese momento se encontraba aún en territorio bajo dominio islámico, o, dicho de otro modo, en territorio no "reconquistado" o aún no reorganizado por el dominio político cristiano. La segunda fecha la ofrece una inscripción descubierta en la misma iglesia y referida a la restauración de la iglesia por el abad Vigila, con un aparejo más perfecto y parecido al de Quintanilla.

Tenemos pues en este caso rel acionada la estratigrafía de la iglesia con los documentos y el paral el o constructivo. La interpretación es lógica y favorable a nuestra postura, pero no deja de haber dudas respecto a la interpolación de Quintanilla o Lara en el documento de Avito, y no deja de plantear problemas la tipología de los aparejos, contradictoria entre sí, pues el aparejo de Quintanilla (si es Sta.
M aría de Lara, citada en 822) se asemeja al del segundo momento de Tobillas (fechado en 939). Si en Bande dudábamos del val or del documento y somos coherentes, nada nos permite actuar de modo contrario en Tobillas. Q uintanilla, que es de sillería, podría ser visigoda y centro de irradiación de las iglesias de sill ería reutilizada o mampostería del grupo, posteriores, de Repoblación; a pesar de lo que esta idea nos pueda repugnar, al existir entre una y otras iglesias más de cien años y la crisis política de la llegada islámica. Al fin y al cabo estaríamos de nuevo en el modelo con que se proponía comprender el documento de Bande. Con los mismos datos podemos proponer interpretaciones distintas. N osotros optamos por la interpretación que unifica todas estas iglesias en el mismo grupo constructivo y socio-cultural, pensando que Quintanilla, sea o no Sta. María de Lara, debe ser posterior a la primera etapa de Tobillas y coetánea a la segunda. A unque no por ello, como vemos, dejen de plantearse problemas.

\section{La tipología de aparejos}

Un ejemplo de la dificultad de trabajar sin cronologías absolutas lo presenta la tipología de los aparejos de estos grupos de edificios que se presentan como un grupo apa- 


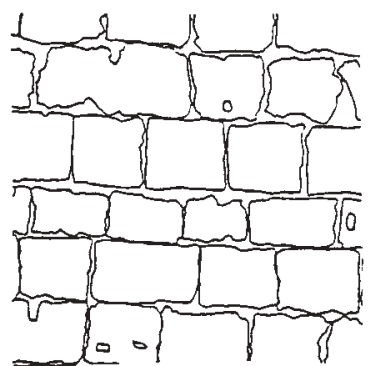

C2 ARLANZA-2

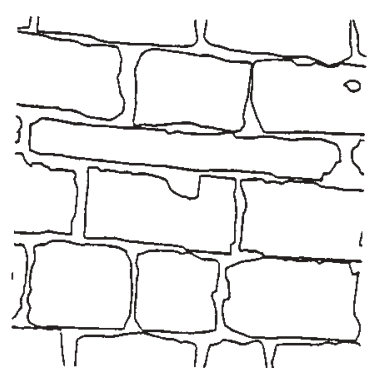

C1 ARLANZA-1

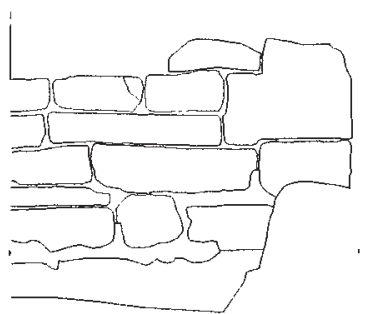

C1 V BLANCAS

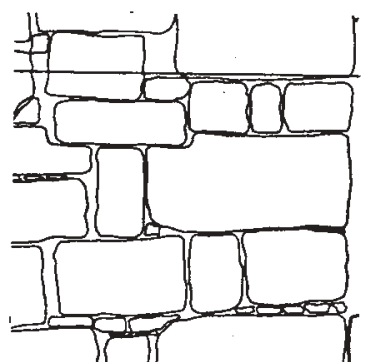

B1 TRAMPAL

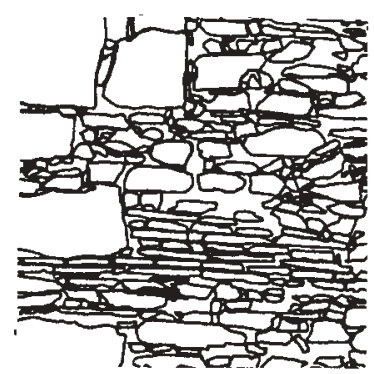

A1/D TRAMPAL

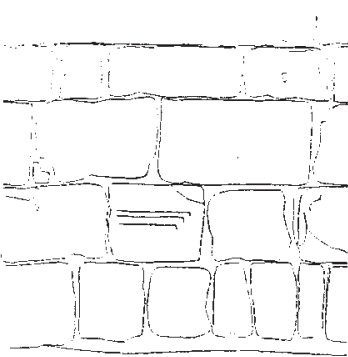

C2 ASUNCIŌN-1

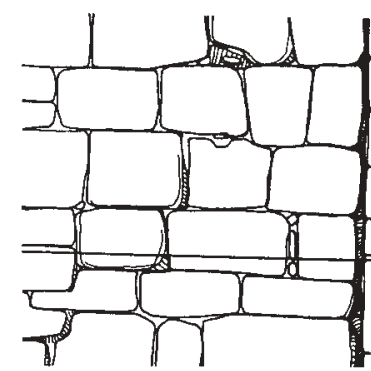

C2 MELQUE-2

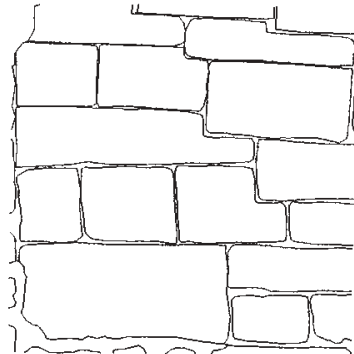

C1 BAÑOS

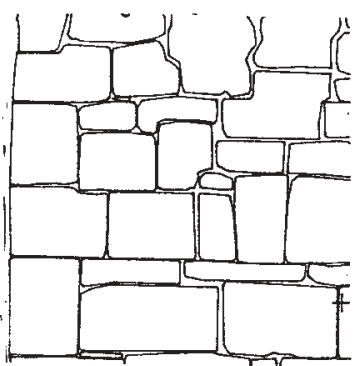

B1 TOBILLAS-1

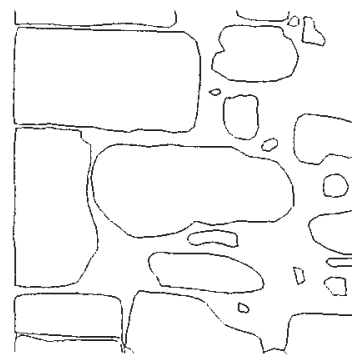

A1 ESCALADA

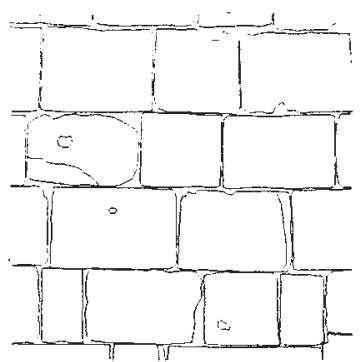

C2 ASUNCIÔN-2

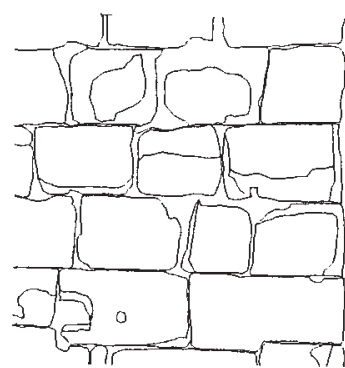

C2 COLOMA

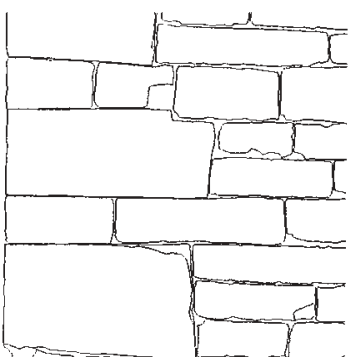

C1 MOROSO

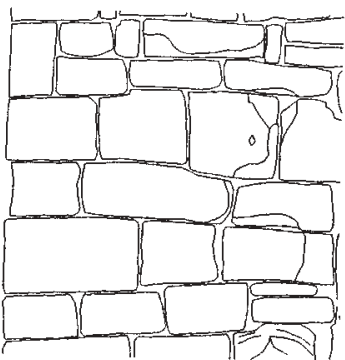

B1 OCA

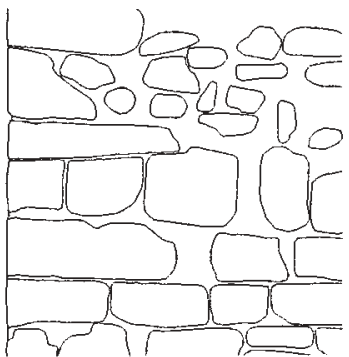

A1 BARRIOSUSO

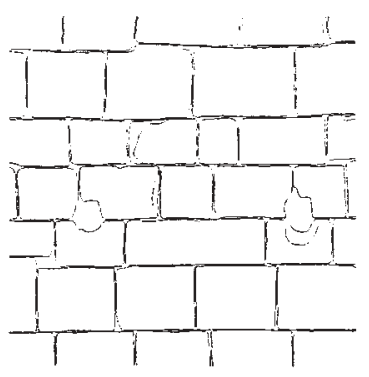

C2 BARBADILLO

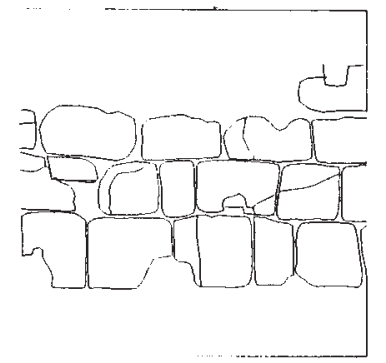

C2 ASUNCIŌN-3

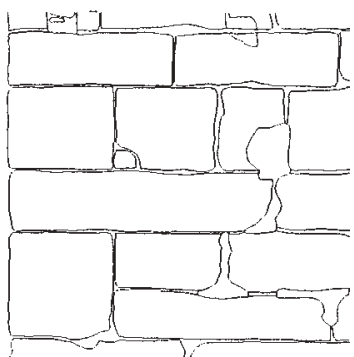

C1 TRICIO-1

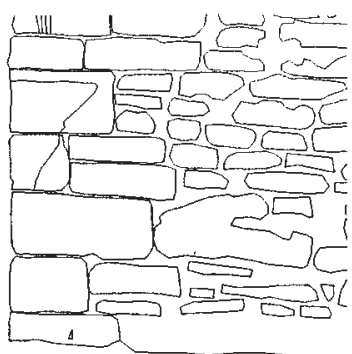

A2 ASUNCIÓN-4

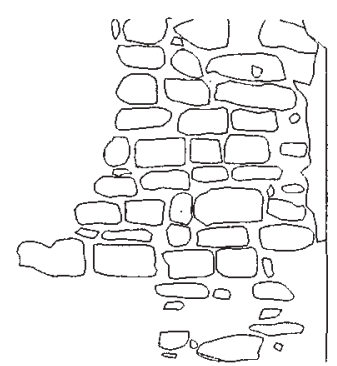

A2 TRICIO-2 


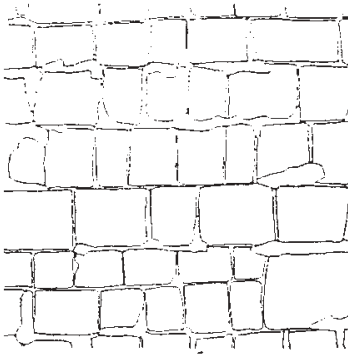

C3 ESCALADA

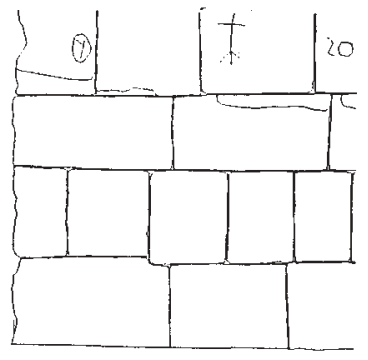

C4 LA NAVE

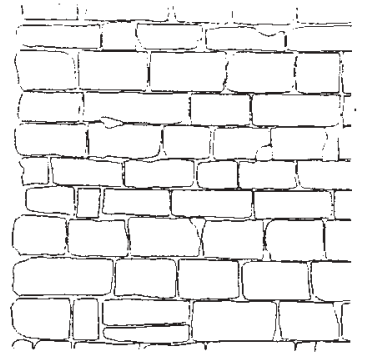

C3 ESCALADA

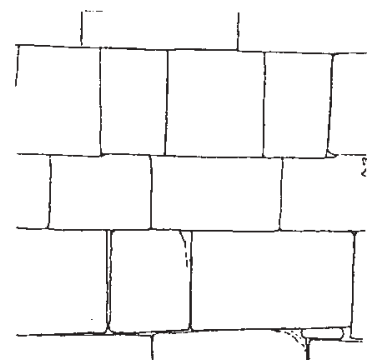

C4 QUINTANa

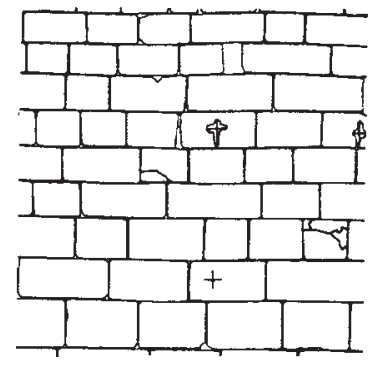

C3 TOBILLAS-2

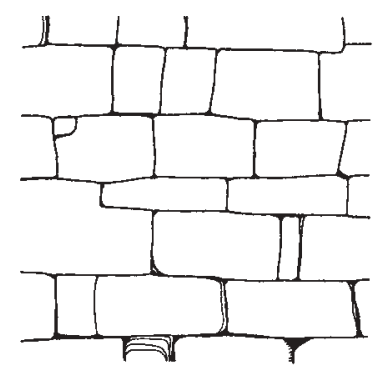

C5 MELQUE-1

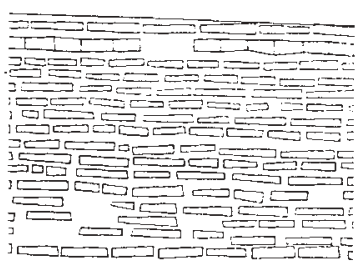

D ESCALADA

Fig.6. Aparejos de iglesias altomedievales españolas (según Caballero 1999)

rentemente falto de homogeneidad formal. Sus diferencias tipológicas parecen sincrónicas. A primera vista los aparejos no nos dicen nada, aún (CABALlero, 1999: 224-225).

M ás que la concreta ausencia de cronología absoluta, es la duda sobre la adscripción cultural y cronológica de los grupos arquitectónicos la que provoca la indecisión sobre su valor cronológico. La ordenación tradicional en grupos tardo antiguos (de transición y visigodo) y medievales (asturiano, de Reconquista, mozárabe, islámico) permite una ordenación cargada de contradicciones internas, como las de hacer depender la aparición de la sillería de la evolución de la mampostería y llevar el curso evolutivo de la sillería sin interrupción a través de la crisis del 700 (ARbelter, 1995).

Pero la reubicación del grupo visigodo entre los medievales provoca la aparente falta de homogeneización a que nos referíamos antes, pues en un tiempo breve se daría una expansión de todos los tipos fundamentales de aparejos (fig. 6). Por ello se puede pensar que encierre distintas fases cronológicas en una evolución rápida o que actúen a la vez distintos grupos culturales/productivos, 0 , simplemente, que faltan datos seguros para ordenar una secuencia tipológica más complicada de lo que aparenta.

Se puede plantear que los aparejos españoles reflejan un sistema complejo y sincrónico como el omeya. La tipología de los aparejos sirios omeyas es muy rica, ofreciendo también Iadrillo, sillería de cantera y reutilizada, mam- postería, y la mezcla de ell os, en una sincronía de menos de dos siglos. Su influjo habría llegado a los ambientes cristianos en impulsos distintos que habrían dado lugar a distintos sub-grupos productivos, cada uno con su propia distribución geográfica, características y cronología y que, a su vez, se habrían interrelacionado entre sí. También se puede plantear, lo que parece más lógico, que actúan dos corrientes diferentes interrelacionadas, una indígena, localista, de trabajo de al bañilería que utiliza mampostería y sillería reutilizada en cadenas (tardorromana), que se difunde por evolución local, y otra ajena (omeya) básicamente de trabajo de cantería con sillería ya fuera reutilizada o de cantera, a la que corresponde el esquema anterior. Es evidente que estas dos corrientes básicas (mampostería y sillería o, mejor, al bañilería y cantería) se multiplican si pasamos del primer escalón productivo a los más complejos de los el ementos singulares, sistemas constructivos y estructural es a los que en última instancia sirven las técnicas de preparación y aparejo del material.

En realidad falta un proyecto de investigación dedicado a esta tipología productiva (no sólo de aparejos) que sólo podría ponerse en marcha si existen las suficientes secuencias estratigráficas previas. Bien es cierto que un problema de los estudios estratigráficos (del que me siento responsable por mi parte) es la ausencia de descripciones de los fósiles directores de la estratigrafía. A nadie extraña que en la excavación se simul tanee la presentación 
estratigráfica con la de la cerámica, principal fósil director tipol ogizado. Esta presencia simultánea es la que teóricamente permite la construcción de tipologías cerámicas, a partir de la excavación, y la que permitiría, en la arquitectura a partir de la lectura de paramentos, la de huellas de uso, aparejos principalmente, elementos singulares y estructurales.

\section{Análisis arqueométrico y cronología absoluta. Los maderos de S. Pedro de La Nave y los ladrillos de Sta. Comba de Bande}

Las hojas de los muros de sillares -sillares probablemente reutilizados y retallados- de La $\mathrm{N}$ ave se reforzaron por medio de grapas de madera, encontradas cuando el edificio se desmontó para cambiarse de lugar. Algo parecido se hizo en el muro de acceso al ábside, por encima del arco de triunfo, con una viga de madera (TORRES BALBÁs, 1933; Caballero, Arce, 1997: 268-269).

El acicate por obtener cronologías absolutas de estas maderas nos decidió a plantear un proyecto de investigación que dirige el químico experto en carbono 14 Fernán Alonso, con la participación del dendrocronólogo Eduardo Rodríguez Trobajo y donde cada disciplina se supone sale ben eficiada con los avances de las otras. Las secuencias dendrocronológicas completas español as no rebasan los siglos XII y X III y sólo en ciertas regiones, por lo que las secuencias obtenidas son flotantes y su cronología se obtiene por carbono $14^{5}$.

La pregunta planteada al análisis era obvia, si la viga era visigoda del siglo VII o de R econquista del IX, y su contestación fue podemos decir que intempestiva, del siglo $\mathrm{V}$ para la fecha del corte, esto es, previa a la fecha más antigua supuesta (Rodríguez, Alonso, CABAllero, 1998). Llamó la atención del dendrocronólogo su madera de pino pinaster y el gran número de anillos, unos 300. Tanto interés como ésta presentan las vigas de Baños (dos cargaderos en la puerta principal y el extremo de una viga aún en su mechinal; además de vigas de atado que lamentablemente se han cubierto antes de poderse analizar), sorprendentemente gemelas de las de La $\mathrm{N}$ ave a pesar de su lejanía geográfica y aún más longevas (de más de 400 años) aunque de una fecha similar de nacimiento. El resultado favorece la comprensión de una producción arquitectónica especializada en la reutilización de materiales para la que, como hemos visto, hay abundantes datos y es normal en la época.

Es distinto el caso de las grapas, aún en proceso de estudio, de madera de encina o quejigo, que obligan a pensar en una cronología inmediata a su uso constructivo. Los resultados de los primeros análisis, aún no definitivos, cen- tran sus fechas en el siglo VII. El útil, el tipo de madera y la técnica utilizada (¿talla en verde con azuela?) hacen suponer que son inmediatas su fabricación y la construcción del edificio. Pero esta propuesta no está confirmada. La madera verde podía producir en el edificio desajustes posteriores que no provocaría la madera curada y no tiene por qué pensarse que su dureza impidiera su talla, pues con una técnica parecida de azuela o destral se talló la sillería de la iglesia, posiblemente reutilizada, sin problemas (CABallero, ArCe, 1997: n. 21). Incluso podría pensarse si se reutilizaron sillares previamente engatillados, con sus propias grapas, que tendrían una apariencia similar a los sillares romanos de la muralla del Tolmo de Minateda en Albacete, de los primeros años de la Era y desmontada a mediados del siglo VI (ABAD, 1996: 80, 103, figs. 4, 40 y 41), pues no puede considerarse que el tiempo pasado entre la obra romana y su reutilización medieval supusiera su imposibilidad si reparamos en que las grapas de La $\mathrm{N}$ ave se conservaron desde el siglo VII o el IX hasta el primer tercio del siglo $X X$ en que se desmontó la iglesia y se recuperaron en buenas condiciones (CABALleRO, 1999: 223-224).

También los análisis por termoluminiscencia de los ladrillos de las bóvedas de Bande ${ }^{6}$ dan una fecha de la segunda mitad del siglo VII para todas las bóvedas accesibles (cuatro), excepto para una que dio una fecha del siglo XIV, compatible con los resultados previos de la lectura estratigráfica que distingue una restauración en la zona donde se obtuvo, por lo que, aunque formalmente nada distingue este ladrillo de los demás, se supone fabricado para la restauración (CABALlero, 2001: 74).

Tanto en el análisis de las grapas, como en el de los ladrillos, vemos que las cronologías absolutas no sólo no son coherentes con el model o propuesto, sino que, aparentemente, favorecen con su cronología el modelo a falsar (siglo VII, grupo visigodo). El impulso inmediato es concluir que estos resultados confirman la certeza del modelo tradicional, obligando a dar marcha atrás en la argumentación, y abandonando el modelo al ternativo.

Pero antes debemos recordar que, tras el resultado de los análisis arqueométricos de la viga de La $\mathrm{N}$ ave, datado su corte en el siglo $\mathrm{V}$, reflexionamos sobre el carácter

\footnotetext{
${ }_{5}$ Plan Nacional de I+D +I (2000-2003). BHA 2000-1221-C02-01, del que forma parte también Antonio Rubinos, en el que se analizan maderas constructivas altomedievales de Baños, Escalada, Berlanga (Alonso, Caballero, Rodríguez, 1997) y Gormaz, además de una cuerda de esparto de los estucos de Melque (RuBIN OS, 1999).

${ }^{6}$ Efectuados en el laboratorio de la U niversidad Autónoma de Madrid bajo la dirección de $\mathrm{D}$ a Mạ. A sunción Millán, igual que los de las tejas del M elque, a que nos referimos más abajo.
} 
pedagógico de este resultado, pues, decíamos: Si suponemos que en vez de dar la fecha c. 400, su fecha hubiera equivalido a la de la primera de las hipótesis, mediados de siglo VII, es probable que hoy estuviéramos considerando la probabilidad de una cronol ogía visigoda para la iglesia deS. Pedro, sin tener en cuenta la relatividad de esta datación (Rodríguez, Alonso, CABAllero, 1998: 293). Esta reflexión permite ahora tomar con cautela el resultado de estas cuatro grapas que parece favorable a la cronología visigoda. Sin embargo, estas maderas también pudieron haberse reutilizado. Su cronol ogía es o coetánea 0 anterior a la fecha de construcción de la iglesia.

En el mismo sentido nos parece igual de problemático el resultado de los ladrillos de Bande que propone la fabricación de ladrillos y por ende la fecha de la iglesia en el siglo VII. Cualquiera de los dos corolarios merece una comprobación rigurosa.

Debemos detenernos a considerar cómo podemos comprender estos resultados. Se enfrentan por un lado los resultados obtenidos por un cuerpo argumental, complejo y aparentemente organizado con rigor al rededor del análisis estratigráfico de las iglesias, que no llega a una conclusión definitiva, pero que ofrece una interpretación histórica coherente a favor del nuevo modelo explicativo; y, por otro, los resultados contradictorios de estos primeros análisis arqueométricos. Ante este dilema no parece lógico aceptar sin más la interpretación más inmediata de los análisis arqueométricos rechazando otras interpretaciones que también pueden plantearse y las que se deriven de los demás tipos de anál isis favorables al nuevo modelo. A ntes debemos efectuar una comprobación. La conclusión lleva de nuevo a completar el proyecto de investigación. Por una parte, ampliando el número de maderas analizadas para comprobar la serie y sus características, proyecto ya en marcha. Por otro, proponiendo otro proyecto que analice por termoluminiscencia los Iadrillos constructivos de las iglesias asturianas y mozárabes, contrastando sus resultados con las previas lecturas estratigráficas y la crítica de los datos documentales a través de los cuales se han datado hasta ahora estas igl esias y de modo que se pueda "cal ibrar" la propia metodol ogía de análisis (como se hace con el carbono-14. Alon SO, 1993; Datació, 1995).

\section{CONCLUSIÓN. ARQUEOLOGIÁA E HISTORIA}

\section{La arqueología de la arquitectura, una disciplina arqueológica e histórica}

H asta aquí y para el caso del paradigma que planteo, los nuevos instrumentos de la A rqueol ogía de la A rquitectura no llegan a una conclusión definitiva. Al contrario, por una parte ofrecen datos sistemáticos, pero no cronologizados, cuya interpretación se puede deducir como favorable al nuevo modelo explicativo; $y$, por otra, datos arqueomé tricos contradictorios con los anteriores, en apariencia favorable al model o explicativo tradicional. Posee un límite esencial mente en la cronología. Mi impresión actual es que esta limitación es propia de esta arqueol ogía y que, en el caso concreto que planteo, será difícil y complicado llegar a una solución más concreta. Esta dificultad o limitación de la arqueología de la arquitectura me ayuda, paradójicamente, a comprenderla vinculada estrechamente a la ciencia histórica y por lo tanto a su uso coordinado con las demás arqueol ogías y ciencias auxiliares de la $\mathrm{H}$ istoria. Es apoyándome en ellas, separándome de la estricta utilización de la arqueología de la arquitectura, como puedo atreverme a dar una explicación histórica al problema planteado, al margen de las contradicciones no resuel tas.

Se dice que la arqueología de la arquitectura no es destructiva y evita la excavación del subsuelo pues la secuencia material que ofrece el edificio no hay que destruirla para analizarla y es semejante a la del yacimiento, cuyo conocimiento es necesariamente destructivo. Esta idea es más aparente que cierta. Ambas ofrecen informaciones de distinto carácter y distinto grado de precisión. Al ofrecer informaciones complementarias se deben tratar como arqueologías complementarias y se debe procurar que el análisis del lugar se efectúe con ambas. Tampoco se debe olvidar que el edificio forma parte del contexto territorial y que por ello se debe analizar también su situación en el entorno, a través de la arqueol ogía del territorio o del paisaje.

\section{Santa Lucía del Trampal y Santa María de Melque y la arqueología de la arquitectura altomedieval}

En El Trampal, la lectura del edificio se hizo concluido el proceso restaurador, perdida la oportunidad de analizar el edificio a la vez que se excavaba, pero existían suficientes datos como para reproducir el proceso de su lectura, de modo que se ha podido documentar la relación directa estratigráfica entre edificio y yacimiento, con la característica nada corriente de que las secuencias de ambas son estrictamente sincrónicas (Caballero, Sáez, 1999: 3179). Mientras que la estratigrafía, en el edificio y en el yacimiento, ordenaba la secuencia de uso/reuso de ambos; la cerámica del yacimiento o los epígrafes, procedentes del edificio y del yacimiento, aportaban datos precisos sobre su cronología proponiéndola como mozárabe del siglo VIII. A demás, su paisaje ofrece indicios de la ordenación del ter- 
ritorio con una explotación hidráulica y agrícola, de la que la iglesia sería su culminación, su imagen simbólica, además de resultado de un centro de producción arquitectónico innovador (CAballero, Sáez, 1999: 323-328).

La conclusión sobre el lugar del Trampal es complementaria de la de Melque, aunque en éste, no se analice estratigráficamente el edificio por la simplicidad de su secuencia (Caballero, Fernández Mier, 1999). Su excavación ofrece abundantes datos sobre el proceso de construcción ex novo de la residencia monástica y de la iglesia, con los suel os de obra, huecos y piletas para el aboración de materiales y morteros. Es la excavación del subsuel o, como en El Trampal, la que ayuda a resolver la cronología del edificio y su conjunto (de nuevo, no sin problemas) por sus cerámicas y los análisis de carbono-14 (entre mediados del siglo VII y la segunda mitad del VIII, que definitivamente rechazan la propuesta tradicional del siglo $X / X I$, RUBIN OS, 1999) y de termoluminiscencia que data en la segunda mitad del siglo VIII la cubierta original de teja del monasterio. Debemos tener, sin embargo, en cuenta que las cerámicas de estos siglos de cambio sólo ahora comienzan a datarse con precisión (CABALlero et alii, en prensa).

M el que pertenece también a una expl otación hidráulica y agrícola como la del Trampal. A mbas explotaciones se pueden explicar, en el marco del nuevo paradigma y de otros modelos como el de Manuel Acién (1998: 48-61), como la puesta en explotación, ex novo, de territorios fundiarios, mano de obra servil y riqueza inmovilizada, de época tardoantigua, visigoda, y probablemente de propiedad eclesiástica, gracias al aporte de nuevas técnicas, facilitadas por el Estado y la sociedad islámicos. Esta aportación no era gratuita, pues el Estado islámico necesitaba crearlas o potenciarlas como modo de incrementar una riqueza necesaria para obtener sus beneficios fiscal es. Estas técnicas, además de hidráulicas y agrícolas, son, a nuestro parecer, constructivas e incluso decorativas. De aquí la importancia que tiene en el nuevo modelo la arqueología real izada en estos lugares que ofrece los primeros datos cronológicamente seguros, con su concorde interpretación histórica, para dos importantes elementos del sistema arquitectónico que anal izamos.

Estos resultados sirven, si no se desmienten, para estos dos lugares y sus iglesias, arranque del grupo prerrománico, pertenecientes a sociedades "mozárabes" antiguas o dimmíes y fechadas en la segunda mitad del siglo VIII o inicios del IX. Pero aún no tenemos resultados de val or similar para el resto de iglesias y sus asentamientos que, según nuestro modelo, podrían ser un siglo posteriores y situadas en territorio de dominio cristiano, como las citadas, entre otras, de Bande, La N ave, Baños y Ias riojanas. Cada una de el las tendrá su propio significado histórico que queda por interpretar.

\section{Bibliografía}

A bAd CASAL L., 1996, La epigrafía del Tolmo de Minateda (H ellín, Albacete) y un nuevo municipio romano del Conventus Carthaginensis, A rchivo Español de A rqueología, 69, pp. 77-108.

ACIÉn A LMANSA M., 1998, La desarticulación de la sociedad visigoda, en Salvatierra Cuenca V. (ed.), Hispania, Al-A ndalus, Castilla. Jornadas H istóricas del A lto G uadalquivir (Quesada 1990), Jaén, pp. 45-67.

Alon SO F., 1995, Consideraciones sobre la calibración, en D atació, pp. 251252.

AlOn SO MatThíAs F., 1993, Carbono 14: calibrar o no calibrar, A rarítica, 5, pp. 3-4.

Alonso Matthías F., Caballero Zoreda L., Rodríguez TROBAJO E., 1997, Cronología constructiva de la iglesia mozárabe de San Baudelio de Berlanga (Soria): primeros resultados de dendrocronología y carbono 14, B ol etín de A rqueología M edieval, 11, pp. 249-263.

ArbeITER A., 1995, Construcciones con sillares. El paulatino resurgimiento de una técnica edilicia en la Lusitania visigoda, en IV Reunió d'A rqueologia Cristiana H ispànica (Lisboa 1992) Barcelona, pp. 211-221.

ARBEITER A., 2000, Alegato por la riqueza del inventario monumental hispanovisigodo, en CABALLERo y MATEOS (eds.), Visigodos y Omeyas. U n debate entre la A ntigüedad Tardía y la alta Edad M edia, A nejos de A EspA 23, pp. 249-263.

A RCE SÁIN Z F., 2001, La escultura arquitectónica altomedieval a la luz de la lectura de paramentos, $V$ Congreso de A rqueología M edieval Española (Valladolid 1999), Actas, T요 1, pp. 263-272.

AZKARATE GARAI-OlAUN A., 1995, Aportaciones al debate sobre la arquitectura prerrománica peninsular: la iglesia de San Román de Tobillas (Álava), A rchivo E spañol de A rqueología, 68, pp. 189-214.

BANGO TORVISO I. G ., 1974, De la arquitectura visigoda a la arquitectura asturiana: los edificios ovetenses en la tradición de Toledo y frente a A quisgrán, L'E urope hérietiére de l'E spagne wisigothique. R encontres de la Casa de Velázquez, 35, Madrid, pp. 303-313.

Bonnet Ch., Beltrán De Heredia Bercero J., 2001, Origen y evolución del conjunto episcopal de Barcino: de los primeros tiempos cristianos a la época visigótica, en Beltrán de Heredia Bercero J., D e Barcino a B arcinona (siglos I-VII). L os restos arqueológi cos de la plaza de R ey, Barcelona, pp. 74-95.

CABALlero Zoreda L., 1987, El método arqueológico en la comprensión del edificio. (Sustrato y estructura), en Curso M ecánica y tecnología de los edificios antiguos, Colegio Oficial de A rquitectos de Madrid, pp. 13-58.

CABAlLero ZOREDA L., 1991, Sobre Santa Comba de Bande (Ourense) y las placas de Saamasas (Lugo), G alicia no tempo, pp. 75-115.

Caballero Zoreda L., 1992, (con la aportación de Mateos Cruz, P.), ¿Visigodo o Asturiano? N uevos hallazgos en Mérida y otros datos para un nuevo "marco de referencia" de la arquitectura y la escultura al tomedieval en el $\mathrm{N}$ orte y el Oeste de la Península Ibérica, 39 Corso di Cultura sull'A rte Ravennate e Bizantina, pp. 139-90.

CABALLER O ZOREDA L., 1994-95, Un canal de transmisión de lo clásico a la al ta Edad M edia española. A rquitectura y escultura de influjo omeya en la Península Ibérica entre mediados del siglo VIII e inicios del siglo X, AlQantara, pp. 25 y 26, 321-348 y 107-124.

CABALLERO ZOREDA L., 1999, Aportación a la arquitectura medieval española. Definición de un grupo de iglesias castellanas, riojanas y vascas, A ctas de $V$ C ongreso de A rqueol ogía M edieval Española (Valladolid), 1, pp. 221233.

Caballero Zoreda L., 2000, La arquitectura denominada de época visigoda, ¿es realmente tardorromana o prerrománica?, en CABALLERo L. y Mateos P. (eds.), Visigodos y Omeyas. U n debate entre la A ntigüedad Tardía y la alta Edad M edia, A nejos de A EspA 23, pp. 207-247. 
Caballero Zoreda L., 2001, Buscando unha Partida de Nacemento. A rqueol oxía da A rquitectura en Santa Comba de Bande (O rense), L ethes 3 , pp. 58-75.

Caballero Zoreda L., Arce F., 1997, La iglesia de San Pedro de La $\mathrm{N}$ ave (Zamora). Arqueología y arquitectura, A rchivo Español de A rqueología, 70, pp. 221-274.

Caballero Zoreda L., Arce Sáinz F., Utrero Agudo Mạ. A., 1999, I glesia altomedieval de Santa Comba de San Torcuato, Bande (Orense). Lectura de paramentos, CSIC, Madrid (manuscrito).

Caballero Zoreda L., Cámara Muñóz L., Latorre GonzÁlez-M ORO P., Matesanz Vera P., 1991/92, La iglesia pre rrománica de S. Pedro el Viejo de A rlanza (H ortigüela, Burgos), N umantia, 5, pp. $139-165$

Caballero Zoreda L., Feijoo S., 1998, La iglesia altomedieval de San Juan Bautista en Baños de Cerrato (Palencia), A rchivo E spañol de A rqueología, 71, pp. 181-242.

Caballero Zoreda L., Fernández Mier M., 1999, Notas sobre el complejo productivo de M elque (Tol edo). Prospección del territorio y análisis de Carbono 14, polínicos, carpológicos y antracológicos y de morteros, A rchivo Español de A rqueología, 72, pp. 199-239.

Caballero Zoreda L., Latorre Macarrón J. I., 1980, La iglesia y el monasterio visigodo de Sta. M a de M el que (Toledo). A rqueología y arquitectura. S. Pedro de la Mata (Toledo) y Sta. Comba de Bande (Orense), en Excavaciones A rqueol ógicas en E spaña, 109.

Caballero Zoreda L., Retuerce Velasco M., Sáez Lara F., (en prensa), Las cerámicas del primer momento de Santa María de Melque (Toledo), construcción, uso y destrucción. Comparación con las de Santa Lucía del Trampal y EI Gatillo (Cáceres), Cerámicas tardorromanas y altomedievales en la Península I bérica: ruptura y continuidad (M érida 2001), A nej os de A E spA .

Caballero Zoreda L., SÁEz F., 1999, La iglesia mozárabe de Santa Lucía del Trampal, Alcuéscar (Cáceres). A rqueología y arquitectura, M emorias A rqueol ógicas de Extremadura, 2. M érida.

CAM Ón AZn AR J., 1963, Arquitectura española del siglo X. M ozárabe y de repoblación, $G$ oya, 52, pp. 206-219.

CAMPS CAZORLA E., 1940, El arte hispano-visigodo, en Historia de España dirigida por R. M enéndez Pidal, III, 2.

Castro M artínez P. V., M Icó Pérez R ., 1995, El C14 y la resolución de problemas arqueológicos. La conveniencia de una reflexión, en $D$ atació, pp. $252-260$

DATACIÓ, 1995, Datació radiocarbònica i calibratge. Debat, Revista d'A rqueol ogia de P onent, 5.

GARCíA DE CORTÁZAR J. A., 1988, Organización social del espacio: propuestas de reflexión y análisis histórico de sus unidades en la España medieval, Studia H istorica. H istoria M edieval 6, pp. 195-236.

GIL J., 1978, Epigraphica III, Cuadernos de F ilología Clásica 14, pp. 83-120.

Góm EZ M OREN O M., 1906, San Pedro de La N ave. Iglesia visigoda, B oletín de la Sociedad Castellana de Excursiones, IV, pp. 365-373.

Gómez M ORENo M., 1919, I glesias M ozárabes, Madrid.

Gómez M OREn O M., 1943-44, Exploraciones en Santa Comba de Bande, B oletín de la Comisión D e M onumentos D e Orense, 14, pp. 47-51.

Gómez M OREN O M., 1966, Primicias del arte cristiano español, A rchivo Español de A rte, 39, pp. 101-139.

Gon ZÁLES BALASCH M los monasteri os y pri oratos 0 anej os a Celanova, Grupo Marcelo M acías y U niv. de Granada, Granada.

GRABAR O. Y A., 1965, L'essor des Arts inspirès par les cours princières à la fin du premier millémai re: princes musulmans et princes chrétiens, Settimane di Studio de Centro Italiano di Studi sull'A Ito M edievo. L'Occidente a I'Islam nell'A Ito M edievo, Spoleto, To 2, pp. 845-901.

GUTIÉRREZ LLORET S., 1997, A rqueología. Introducción a la historia material de las sociedades de pasado, U niversidad de Alicante.

J ORGE ARAGONESES M., 1957, El primer Credo epigráfico y otros restos coetáneos, descubiertos en Toledo, A rchivo E spañol de A rte 30, pp. 295-323.

J UAN E., LERMA J. V., 2000, La villa áulica del "Pla de N adal" (Riba-Roja de Túria), en RIBERA I LACOMBA, A. (coord.), L os orígenes del cristianismo en Valencia y su entorno, Valencia, pp. 135-142.
J UNYENT E., LÓPEZ J. B., MARTín A., 1995, Datació radiocarbònica i calibratge, en D atació, pp. 250-251.

LAM PÉREZ y ROMEA V., 1908, H istoria dela A rquitectura Cristiana Española de la Edad M edia, Madrid.

Mateos Cruz P., 1999, Excavaciones en la basílica de Santa Eulalia de Mérida. A rqueología y U rbanismo, A nejos de A EspA, 19.

Mateos Cruz P., Alba Calzado M., 2000, De Emerita Augusta a $M$ arida, en CABallero y Mateos (edit.), Visigodos y Omejas. U $n$ debate entre la A ntigüedad Tardía y la alta Edad M edia, A nejos de A E spA 23, pp. 143-168.

MESTRES J. S., 1995, La datació per radiocarboni i el calibratge de les dates radiocarbòniques. O bjectiu, problemesi aplicacions, en D atació, pp. 261-275.

N UÑEZ RodRíGUEZ M., 1978, Arquitectura prerrománica, Historia da A rquitectura $G$ al ega, Col exio de A rquitectos de $G$ alicia.

Palol I Salellas P. DE., 1968, A rte hispánico de la época visigoda, Barcel ona Palol I Salellas P. DE, 1988, La baślica de San Juan de B años, Palencia.

Palol I SAlellas P. DE, 1991, España Visigoda. Arte y Arqueología, en H istoria de España dirigida por R. Men Éndez PIDAL, Madrid, III.

PeÑA Bocos E., 1995, La atribución social de espacio en la Castilla altomedie val, U niversidad de Cantabria, Sal amanca.

PUIG I CADAFALCH J., 1961, L'art visigothique et ses survivances: recherches sur les origines et le dével oppement de l'art en F rance et en Espagne du IV e au X II e siéde, Paris.

REAL M . L., 1995, Inovaçâo e resistência: dados recentes sobre a antiguidade cristâ no ocidente peninsular, IV Reunió d'A rqueologia Cristiana H ispànica (Lisboa 1992), Barcelona, pp. 17-68.

REAL M. L., 2000, Portugal: Cultura visigoda e cultura moçárabe, en Caballero L. y Mateos P. (eds.), Visigodos y Omeyas. Un debate entre la A ntigüedad Tardía y la alta Edad M edia, A néos de A E spA, 23, pp. 21-75.

Ribera I Lacomba A., Roselló Mesquida M., 2000: El primer grupo episcopal de Valencia, en RIBERA I LACOMBA A. (coord.), Los orígenes del cristianismo en Valencia y su entorno, Valencia, pp. 165-185.

Rodríguez Trobajo E., Alonso Matthías F., Caballero ZoREDA L., 1998, Datación de una viga de la iglesia de San Pedro de La $\mathrm{N}$ ave (Zamora), A rchivo E spañol de A rqueología, 71, pp. 283-294.

RuBin OS PÉREZ A., 1999, Anexo 2. Datación por carbono-14 del yacimiento de Santa M aría de M elque, A rchivo E spañol de A rqueología, 72, pp. 220-226.

SÁN CHEZ GARCíA J. L., 2001, I glesia de San J uan B autista. A rte, arquitectura y arqueol ogismo en $B$ años de $C$ errato, Colegio O ficial de Arquitectos de León.

SCH LUNK H ., 1945, Observaciones en torno al problema de la miniatura visigoda, A rchivo Español de A rte, 71, pp. 241-265.

SCH LUNK H ., 1970, Beiträge zur K unstgeschichtlichen Stell lung Tol edos im 7. J ahrhundert, M adrider M ittélungen, 11, pp. 161-86, lám. 43-60.

SCHLUNK H ., 1980, El arte asturiano en torno al 800, A ctas de Simposio para el estudio de los códices de "Comentario al A pocalipsis de B eato de L iébana", M adrid 1, pp. 1-2, 135-164 y 87-120.

SCHLUNK H ., H AUSCHILD TH., 1978, Die Denkmäler der früchristlichen und westgotischen Zeit, en $\mathrm{H}$ ispania A ntiqua, Mainz am Rhein.

SORIAN O SÁn CHEZ R., 2000, El monumento funerario de la cárcel de San Vicente y las tumbas privilegiadas, en RIBERA I LACOMBA A. (coord.), L os orígenes del cristianismo en Valencia y su entorno, Valencia, pp. 187-192.

TORRES BALBÁs L., 1933, La reparación de los monumentos antiguos en España II, A rquitectura. Colegio Oficial de A rquitectos, XV, pp. $129 \mathrm{ss.}$

U LBERT H.T., 1973, Die Westgotenzeitliche Kirche von Valdecebadar be Olivenza, M adrider M itteilungen, 14, pp.202-216. Reeditado en 1997: La igle sia de época visigoda de Valdecebadar en las proximidades de Olivenza, Encontros Encuentros, 3, pp. 117-143.

VELÁZQUEZ I., H ERN AN DO R ., 2000, U na noticia desconcertante sobre la inscripción de San J uan de Baños ofrecida por Álvar Gómez de Castro, A rchivo E spañol de A rqueol ogía, 73, pp. 295-308. 